Louisiana State University

LSU Digital Commons

Faculty Publications

Department of Biological Sciences

$1-1-2020$

\title{
Molecular responses to freshwater limitation in the mangrove tree Avicennia germinans (Acanthaceae)
}

\author{
Mariana Vargas Cruz \\ Universidade Estadual de Campinas \\ Gustavo Maruyama Mori \\ UNESP-Universidade Estadual Paulista \\ Dong Ha Oh \\ Louisiana State University \\ Maheshi Dassanayake \\ Louisiana State University \\ Maria Imaculada Zucchi \\ São Paulo Agency for Agribusiness Technology
}

See next page for additional authors

Follow this and additional works at: https://digitalcommons.Isu.edu/biosci_pubs

\section{Recommended Citation}

Cruz, M., Mori, G., Oh, D., Dassanayake, M., Zucchi, M., Oliveira, R., \& Souza, A. (2020). Molecular responses to freshwater limitation in the mangrove tree Avicennia germinans (Acanthaceae). Molecular Ecology, 29 (2), 344-362. https://doi.org/10.1111/mec.15330

This Article is brought to you for free and open access by the Department of Biological Sciences at LSU Digital Commons. It has been accepted for inclusion in Faculty Publications by an authorized administrator of LSU Digital Commons. For more information, please contact ir@lsu.edu. 


\section{Authors}

Mariana Vargas Cruz, Gustavo Maruyama Mori, Dong Ha Oh, Maheshi Dassanayake, Maria Imaculada Zucchi, Rafael Silva Oliveira, and Anete Pereira de Souza 


\title{
Molecular responses to freshwater limitation in the mangrove tree Avicennia germinans (Acanthaceae)
}

\author{
Mariana Vargas Cruz ${ }^{1}$ (D) | Gustavo Maruyama Mori ${ }^{2}$ (D) | Dong-Ha $\mathrm{Oh}^{3}$ (D) | \\ Maheshi Dassanayake ${ }^{3}$ (D) \\ Maria Imaculada Zucchi ${ }^{4}$ (i) \\ Rafael Silva Oliveira ${ }^{1}$ \\ Anete Pereira de Souza ${ }^{1}$
}

${ }^{1}$ Department of Plant Biology, Institute of Biology, University of Campinas (Unicamp), Campinas, Brazil

${ }^{2}$ Institute of Biosciences, São Paulo State University (Unesp), São Vicente, Brazil

${ }^{3}$ Department of Biological Sciences, Louisiana State University (LSU), Louisiana, LA, USA

${ }^{4}$ São Paulo Agency for Agribusiness Technology (APTA), Piracicaba, Brazil

Correspondence

Anete Pereira de Souza, Department of Plant Biology, Institute of Biology, University of Campinas (Unicamp), Campinas, Brazil. Email: anete@unicamp.br

Funding information

Conselho Nacional de Desenvolvimento Científico e Tecnológico, Grant/Award Number: $309661 / 2014-5$ and 448286/20149; Fundação de Amparo à Pesquisa do Estado de São Paulo, Grant/Award Number: 2011/52072-0, 2013/080861, 2013/26793-7 and 2014/22821-9; Coordenação de Aperfeiçoamento de Pessoal de Nível Superior, Grant/ Award Number: 88882.160095/2013$01,88887.177158 / 2018-00$ and 99999.008084/2015-07; National Academy of Sciences, Republic of Korea, Grant/ Award Number: PJ01317301; Center for Hierarchical Manufacturing, National Science Foundation, Grant/Award Number: MCB 1616827

\begin{abstract}
Environmental variation along the geographical space can shape populations by natural selection. In the context of global warming and changing precipitation regimes, it is crucial to understand the role of environmental heterogeneity in tropical trees adaptation, given their disproportional contribution to water and carbon biogeochemical cycles. Here, we investigated how heterogeneity in freshwater availability along tropical wetlands has influenced molecular variations of the black mangrove (Avicennia germinans). A total of 57 trees were sampled at seven sites differing markedly in precipitation regime and riverine freshwater inputs. Using 2,297 genome-wide single nucleotide polymorphic markers, we found signatures of natural selection by the association between variations in allele frequencies and environmental variables, including the precipitation of the warmest quarter and the annual precipitation. Additionally, we found candidate loci for selection based on statistical deviations from neutral expectations of interpopulation differentiation. Most candidate loci within transcribed sequences were functionally associated with central aspects of drought tolerance or plant response to drought. Moreover, our results suggest the occurrence of the rapid evolution of a population, probably in response to sudden and persistent limitations in plant access to soil water, following a road construction in 1974. Observations supporting rapid evolution included the reduction in tree size and changes in allele frequencies and in transcript expression associated with increased drought tolerance through the accumulation of osmoprotectants and antioxidants, biosynthesis of cuticles, protection against protein degradation, stomatal closure, photorespiration and photosynthesis. We describe a major role of spatial heterogeneity in freshwater availability in the specialization of this typically tropical tree.
\end{abstract}

\section{KEYWORDS}

Avicennia germinans (Black Mangrove), drought-tolerance, ecological genomics, nextRAD, RNA-Seq, tropical tree 


\section{1 | INTRODUCTION}

Natural ecosystems are characterized by wide environmental heterogeneity over geographical space. These spatial variations in several abiotic conditions can shape population specializations, particularly in widespread species, through changes in the frequency of genotypes and phenotypes (Kawecki \& Ebert, 2004). Therefore, environmental gradients represent natural laboratories for the study of environmental selection (De Frenne et al., 2013). As sessile organisms, incapable of escaping from unfavourable conditions, plants are ideal models for investigating adaptation through phenotypic plasticity and/or adaptive genetic variation. They are often subject to a wide range of environmental factors, such as water, light, temperature and nutrient availability. Among the various environmental factors that determine adaptive phenotypic and genotypic diversity in plants, freshwater availability plays a prominent role (Choat et al., 2018; Phillips et al., 2010). Accordingly, population differentiation in drought tolerance has been widely identified in various studies, providing valuable insights into the evolutionary consequences of spatial variation in freshwater availability in plant species (Aranda et al., 2014; Donovan, Ludwig, Rosenthal, Rieseberg, \& Dudley, 2009; Etterson, 2004; Heschel \& Riginos, 2005; Keller et al., 2011; Ramírez-Valiente et al., 2018). Reduced freshwater availability resulting from the combination of high atmospheric temperature with low rainfall and air humidity represents a major threat to plants, especially trees and the forest ecosystems that they form (Asner et al., 2016; Bennett, McDowell, Allen, \& Anderson-Teixeira, 2015; McDowell \& Allen, 2015). These changes influence major components of resource use by reducing the soil water potential, which limits the water and nutrient supply to leaves, and by raising the air vapour pressure deficit (VPD), which increases water loss through transpiration (McRae, 1980; Novick et al., 2016). In response to these conditions, plants close their stomata (McAdam \& Brodribb, 2015; Tyree \& Sperry, 1989), thereby decreasing the chance of death from hydraulic failure (Rowland et al., 2015) despite causing negative impacts on photosynthesis and productivity (Lawlor, 2002).

Currently, there is great interest in understanding the genotypic and phenotypic bases of tree resistance to drought, as these mechanisms are key to improving predictions of the environmental consequences of extreme events and to developing plans to mitigate forest loss (Corlett, 2016; da Costa et al., 2010; Phillips et al., 2009). Substantial advances in the understanding of phenotypic characteristics that enhance drought tolerance in trees have been achieved recently (Bartlett, Scoffoni, \& Sack, 2012; Bennett et al., 2015; Hacke, Sperry, Wheeler, \& Castro, 2006; Powell et al., 2017); however, little is known about the molecular basis of water stress tolerance, particularly in tropical species (Holliday et al., 2017), which contribute disproportionally to the global carbon cycle (Corlett, 2016).

In this study, we investigated the role of environmental selection along a gradient of freshwater availability in shaping the molecular variation of a typically tropical and abundant tree, Avicennia germinans (L.) L. (Acanthaceae). During dry seasons, VPD, soil salinity and water deficits can reach extreme levels in tropical zones, hindering the maintenance of water and ion homeostasis and limiting carbon gain and plant growth (Clough, Sim, Inlet, Bay, \& Rivers, 1989; Lin \& Sternberg, 1992). Thus, we hypothesized that spatial heterogeneity in freshwater availability shapes adaptive variation in the allele frequencies and the expression profiles of transcripts of tropical trees associated with the response to and tolerance of limited freshwater. Avicennia germinans individuals were sampled along a wide longitudinal range in the equatorial Brazilian coastline, an area showing narrow spatial heterogeneity in temperature seasonality but encompassing high variation in the intensity and duration of the dry season, in annual precipitation levels and in riverine freshwater input, which influence levels of soil salinity (Figure 1). We used the Nextera-tagmented reductively amplified DNA (nextRAD) sequencing approach for the identification and genotyping of genome-wide single nucleotide polymorphisms (SNPs). We analyzed the organization of the genetic structure and performed statistical tests to identify candidate loci for selection. To minimize false positives in the detection of candidate loci (Lotterhos \& Whitlock, 2015), we used distinct approaches: (a) based on the identification of loci deviating from neutral models of interpopulational genetic variation (FST outlier tests) and (b) based on direct genetic-environment (G-E) association tests. RNA sequencing (RNA-Seq) was used to assemble and characterize the transcriptome of the species, providing a functional basis for the annotation of candidate loci for selection. Additionally, we examined the role of molecular adaptation to extreme soil freshwater limitation via differential gene expression analysis between samples from adjacent sites differing in tidal inundation frequency (Lara \& Cohen, 2006; Pranchai et al., 2017), acclimated in pots under homogeneous, watered conditions. Our results provide converging signs of adaptive responses of $A$. germinans to the environmental heterogeneity in freshwater availability, including a case that suggests the rapid evolution of a population, with changes in phenotype and in the genetic profile. We highlight the relevance of environmental heterogeneity in freshwater availability as a key selective pressure in tropical tree species.

\section{2 | MATERIALS AND METHODS}

\section{1 | Study system}

As with any mangrove tree, Avicennia germinans L. (L.) naturally experiences daily and seasonal fluctuations in temperature, air humidity, freshwater inputs and soil salinity (Tomlinson, 1986). However, this species is particularly suitable for the study of the mechanisms underlying tree adaptation to drought since it belongs to the mangrove genus most tolerant to conditions limiting water acquisition, such as drought, freezing and salinity (Pranchai et al., 2017; Reef \& Lovelock, 2015; Stuart, Choat, Martin, Holbrook, \& Ball, 2007). Moreover, it presents a generalist insect pollination system (Nadia, Menezes, \& Machado, 2013), and although it is predominantly outcrossing, it also supports self-fertilization (Mori, Zucchi, \& Souza, 2015; Nettel-Hernanz, Dodd, Ochoa-Zavala, Tovilla-Hernández, \& Días-Gallegos, 2013). Additionally, A. germinans reproduces by producing cryptoviviparous, buoyant, and salt-tolerant propagules, 
(a)

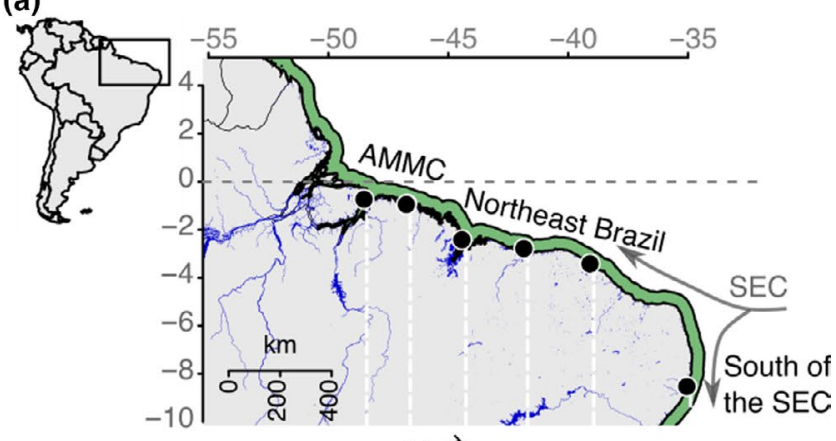

FIGURE 1 Avicennia germinans sampling sites along a lowlatitude salinity and precipitation gradient. (a) Top: Geographical location of the study area and sampling sites. Black points represent sampling sites, green areas represent the occurrence of the species, and blue areas represent ponds and rivers. Bottom: Environmental variation based on sea surface salinity and precipitation variables across sampling sites (

source: WORLDCLIM and MARSPEC). AMMC: Amazon Macrotidal Mangrove Coast; SEC: South Equatorial Current. (b) Bidimensional projection of sampling sites based on a principal component analysis. PC1 and PC2 retained $79.7 \%$ of the variance of noncollinear environmental variables (eigenvectors). AnnP: annual precipitation; MinVap: minimum air water vapour pressure; MinTCM: minimum temperature of the coldest month; SSTCM: sea surface temperature of the coldest month; MeanSST: mean sea surface temperature; MeanSSS: mean sea surface salinity; PWarmQ: precipitation of the warmest quarter; MaxRad: maximum solar radiation; SSTRange: sea surface temperature range; PDM: precipitation of the driest month [Colour figure can be viewed at wileyonlinelibrary.com]

Precipitation of the warmest quarter $(\mathrm{mm})$

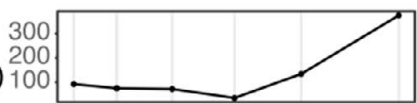

Precipitation of the driest month $(\mathrm{mm})$

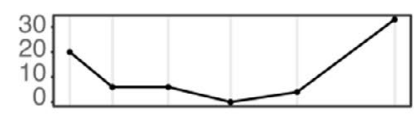

(b)

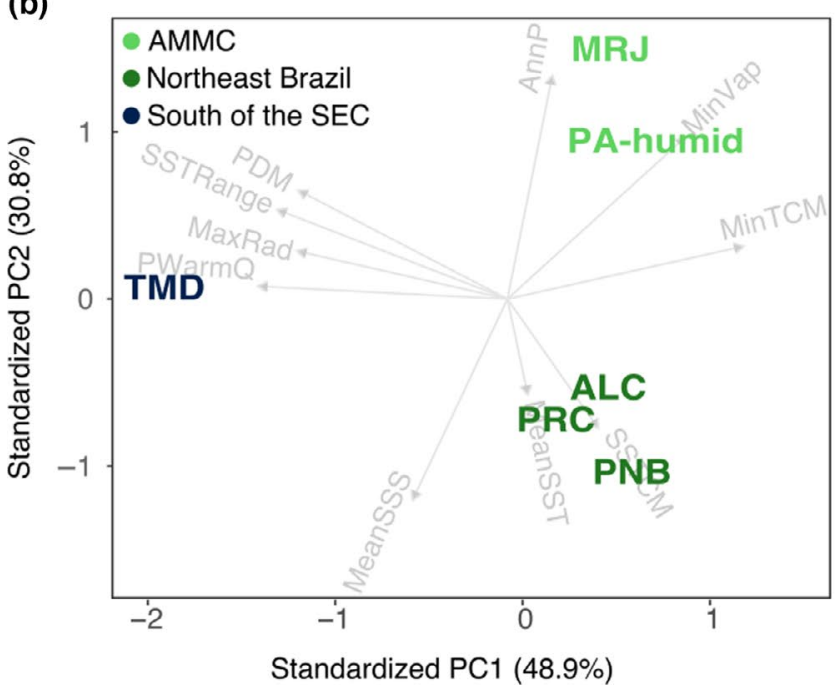

which enables long-distance and even transoceanic dispersal (Mori, Zucchi, Sampaio, \& Souza, 2015; Tomlinson, 1986). This set of characteristics contributes to making $A$. germinans one of the most widespread mangroves in the Atlantic East-Pacific biogeographic region (Ellison, Farnsworth, \& Merkt, 1999).

\section{2 | Study area}

Sampling sites were located over more than $1,800 \mathrm{~km}$ of the northeast Brazilian coastline, between $0.724^{\circ} \mathrm{S}$ and $8.526^{\circ} \mathrm{S}$ latitude and along a spatial gradient in freshwater availability (Table 1; Figure 1a). We obtained environmental data for each sampling site, consisting of 21 bioclimatic and oceanographic variables from the public databases

WORLDCLIM (Hijmans, Cameron, Parra, Jones, \& Jarvis, 2005; 15 precipitation, radiation and air vapour pressure layers) and MARSPEC (Sbrocco \& Barber, 2013; four sea surface salinity and temperature layers). To minimize the collinearity of variables, we used a correlation threshold of 0.8 (Figure S1). We classified the study area into three distinguishable regions based on a principal component analysis of the environmental data set (Figure 1b): (a) the Amazon Macrotidal Mangrove Coast (AMMC), the world's largest continuous mangrove belt (Nascimento, Souza-Filho, Proisy, Lucas, \& Rosenqvist, 2013), which has a mean annual precipitation above $2,000 \mathrm{~mm}$ /year and is influenced by the mouth of the Amazon River; (b) mangroves of Northeast Brazil, which show limited forest development (Schaeffer-Novelli et al., 1990) and are characterized by a lack of riverine freshwater inputs and a mean annual precipitation below $2,000 \mathrm{~mm}$ /year, with pronounced and long dry seasons and less than $30 \mathrm{~mm}$ of precipitation in the driest quarter; and (c) a region influenced by the southward-flowing branch of the South Equatorial coastal current (South of the SEC), characterized by

TABLE 1 Characterization and geographic location of Avicennia germinans sampling sites

\begin{tabular}{llllll} 
& & & \multicolumn{2}{c}{ Number of samples } \\
\cline { 4 - 5 } $\begin{array}{l}\text { Sampling } \\
\text { site ID }\end{array}$ & $\begin{array}{l}\text { Climate } \\
\text { classification }^{\text {a }}\end{array}$ & $\begin{array}{l}\text { Latitude; } \\
\text { longitude }\end{array}$ & nextRAD & RNA-Seq \\
\hline MRJ & Am & $00.72 \mathrm{~S} ; 48.49 \mathrm{~W}$ & 8 & - \\
\hline PA-arid & b & Am & $00.90 \mathrm{~S} ; 46.69 \mathrm{~W}$ & 9 & 3 \\
\hline PA-humid & Am & $00.94 \mathrm{~S} ; 46.72 \mathrm{~W}$ & 9 & 3 \\
\hline ALC & Aw & $02.41 \mathrm{~S} ; 44.41 \mathrm{~W}$ & 5 & - \\
\hline PNB & Aw & $02.78 \mathrm{~S} ; 41.82 \mathrm{~W}$ & 9 & - \\
\hline PRC & Aw & $03.41 \mathrm{~S} ; 39.06 \mathrm{~W}$ & 7 & - \\
\hline TMD & As & $08.53 \mathrm{~S} ; 35.01 \mathrm{~W}$ & 10 & - \\
\hline
\end{tabular}

${ }^{a}$ Köppen-Geiger climate classification system (Alvares, Stape, Sentelhas, Gonçalves, \& Sparovek, 2013). Am, tropical monsoon climate; Aw, Tropical wet savanna climate; As, Tropical dry savanna climate.

${ }^{b}$ Samples from a forest flooded exclusively during spring tides (Lara \& Cohen, 2006). 
the presence of scattered estuaries, with a mean annual precipitation of approximately $1,000 \mathrm{~mm} /$ year and a mild dry season with more than $100 \mathrm{~mm}$ of precipitation in the driest quarter.

In the $A M M C$, we visited two adjacent sites (which require a more detailed description), both located on the peninsula of Ajuruteua, state of Pará, Brazil (Figure 2a). The peninsula was covered by a well-preserved, daily-flooded mangrove forest (Cohen \& Lara, 2003) until it was divided by the construction of a road (Figure 2b) in 1974. The hydrology of the area was then dramatically changed, and a part of the forest started flooding exclusively during the highest spring tides of only one out of the two estuaries surrounding the peninsula (Figure 2a). The changed hydrology resulted in forest dieback and subsequent recolonization of the degraded area, mainly by A. germinans. Pore water salinity accumulated to extremely high levels (100 ppt at $50 \mathrm{~cm}$ depth), and the air surface temperature frequently exceeded $40^{\circ} \mathrm{C}$ (Vogt et al., 2014). These environmental features contributed to the dwarfism of recolonizing individuals (Cohen \& Lara, 2003; Pranchai et al., 2017), whose shrub architecture (up to $2.0 \mathrm{~m}$ in height) contrasts the former tall morphology (up to $30 \mathrm{~m}$ in height), which is still observed in surrounding areas where the hydrology remained unaltered (Menezes, Berger, \& Mehlig, 2008; Figure 2b). Throughout this work, we refer to the western side of the road as "PA-arid" and the eastern side as "PA-humid".

\section{3 | Population genetics}

\subsection{1 | DNA extraction and sequencing}

Leaves from 57 adult $A$. germinans trees were sampled from seven distinct sites (Table 1) and stored in bags with silica gel. DNA extraction was performed using the DNeasy Plant Mini Kit (Qiagen) and NucleoSpin Plant II (Macherey Nagel). DNA quality and quantity were assessed using $1 \%$ agarose gel electrophoresis and the QuantiFluor dsDNA system in a Quantus fluorometer (Promega). NextRAD libraries were constructed by SNPsaurus (SNPsaurus, LLC; Russello, Waterhouse, Etter, \& Johnson, 2015). Genomic DNA fragmentation and short-adapter ligation were performed with Nextera reagent (Illumina, Inc.), followed by amplification, in which one of the primers matched the adapter and extended it by nine arbitrary nucleotides of DNA. Thus, amplicons were fixed at the selective end, and their lengths depended on the initial fragmentation, leading to consistent genotyping of amplified loci. Subsequently, nextRAD libraries were sequenced in a HiSeq 2500 (Illumina, Inc) with 100 bp single-end chemistry (Figure S2).

\subsection{2 | SNP detection and genotyping}

Genotyping-by-sequencing used custom scripts from our sequencing service facility, SNPsaurus LLC, to create a reference catalogue of abundant reads. Read mapping to the catalogue allowed two (a)

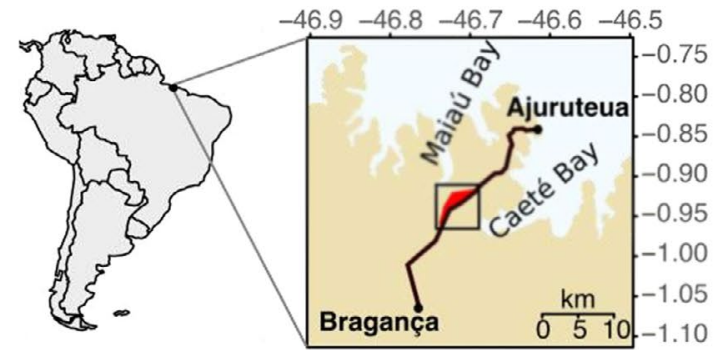

(b)

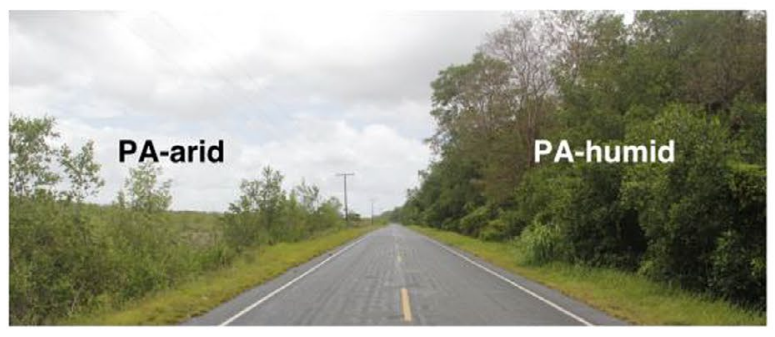

(c)

Collection of similarly sized seedlings in contrasting field conditions
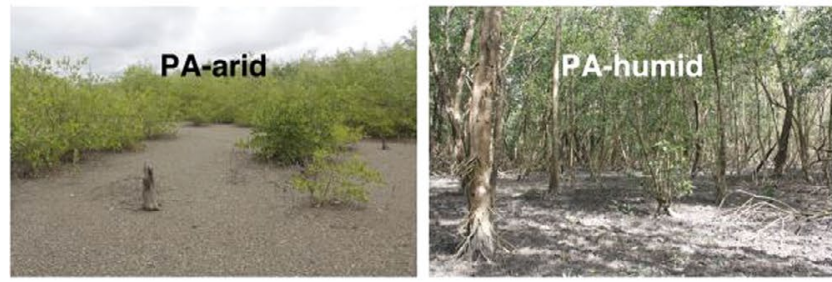

Transplantation into pots and acclimation in open air under shaded, well-watered conditions for three days

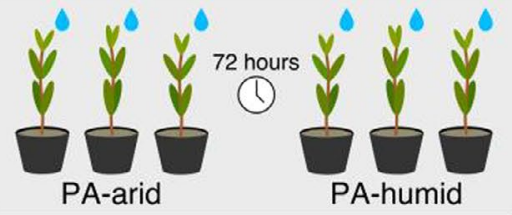

Plant material harvested for RNA-sequencing, followed by analyses of differential transcript expression levels

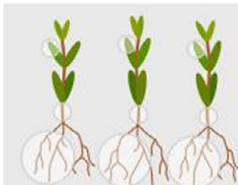

PA-arid
VS.

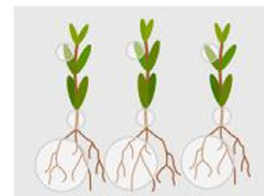

PA-humid
FIGURE 2 PA-arid and PA-humid sampling sites and RNA sequencing (RNA-Seq) experimental design. (a) Geographical location of sites, highlighted by a square (red coloured area is the PA-arid site). (b) Photograph of a section of the Bragança-Ajuruteua road (Pará, Brazil) along which severe changes in hydrology altered the mangrove community and tree morphology. (c) RNA-Seq experimental design. Photographs: G.M. Mori and M.V. Cruz [Colour figure can be viewed at wileyonlinelibrary.com]

mismatches. Biallelic loci present in at least $10 \%$ of samples were selected for the subsequent steps. Using vcFTools 0.1.12b (Danecek et al., 2011), we selected high-quality sequences (Phred score $>30$ ), allowing a maximum of $65 \%$ missing data and one SNP per sequence, requiring a minimum coverage of $8 \times$ and a minor allele frequency $\geq 0.05$ (Figure S2). To reduce false SNP detection rates due to 
paralogy or low-quality genotype calls, we used a maximum read of 56 , resulting from the product of the average read depth and 1.5 standard deviation of the mean.

\subsection{3 | Genetic diversity analysis and identification of candidate SNP loci associated with water-stress tolerance}

For each sampling site, we estimated the genetic diversity using persite nucleotide diversity $(\pi)$, calculated using VCFTOoLs (Danecek et al., 2011); we identified private alleles $(\mathrm{pA})$, observed $\left(H_{\mathrm{O}}\right)$ and expected $\left(H_{\mathrm{E}}\right)$ heterozygosities using POPPR 2.8.2 (Kamvar, Tabima, \& Grünwald, 2014); and we determined the percentage of polymorphic loci (\%Poly) using ADEGENET 2.1.1 (Jombart \& Ahmed, 2011). We also estimated pairwise genetic differentiation (FST), the inbreeding coefficient (FIS) and its 95\% confidence interval through 1,000 bootstrap resampling over all SNP loci using HIERFSTAT 0.04-22 (Goudet, 2005). The genetic structure of $A$. germinans was described by a multivariate model-free method, a discriminant analysis of principal components (Jombart, Devillard, \& Balloux, 2010), and ADMIXTURE 1.3.0 (Alexander, Novembre, \& Lange, 2009). We considered numbers of groups from 1 to 50 and the Bayesian information criteria to determine the number of groups (K). The OPTIM.A.SCORE function was used to avoid overfitting during discrimination steps (Jombart, 2008). For ADMIXTURE analysis, we performed three separate runs for values of $K$ varying from 1 to 15 using the block-relaxation method for point estimation. Computing was terminated when estimates increased by less than 0.0001 . The lowest level of cross-validation error indicated the most likely $K$-value.

To detect signatures of natural selection, we used three distinct methods. Loci that were highly correlated with the environmental structure (false discovery rate $(F D R)<0.05$ ) were detected using the R package LEA (Frichot \& François, 2015), which is based on analyses of genetic structure and ecological association (G-E association tests). In these analyses, we used noncollinear environmental bioclimatic and oceanographic variables (Figure S1) retrieved from the public databases WORLDCLIM (Hijmans et al., 2005; precipitation, radiation and air vapour pressure layers) and MARSPEC (Sbrocco \& Barber, 2013; sea surface salinity and temperature layers). Since the environmental divergence between PA-arid and PA-humid is evident (Figure 2) but undistinguishable based on the highest-resolution environmental data sets, we excluded PA-arid samples from G-E association tests.

To overcome limitations in the acquisition of environmental data for the PA-arid site, two other methods were used to detect candidate loci for selection. These methods are based solely on deviations from neutral expectations of allele frequency distributions, regardless of environmental variation data across sampling sites (FST outlier tests). With PCADAPT 2.0 (Luu, Bazin, \& Blum, 2016), population structure was determined by a principal component analysis. A disproportional relation to this structure $(F D R<0.05)$ was indicative of selection. With Lositan (Antao, Lopes, Lopes, Beja-Pereira, \& Luikart, 2008), which uses the FDIST2 method (Beaumont \& Nichols, 1996), we assessed the relationship between FST and $H_{E}$ to describe the neutral distribution under an island migration model. Hence, we detected loci with excessively high or low FST. Because Lositan may show partially divergent results among independent simulations, we only considered candidate loci conservatively identified in three independent Lositan simulations assuming an infinite allele model of mutation, with a confidence interval of 0.99 and an FDR $<0.05$, using the neutral mean FST and forcing the mean FST options.

Demographic histories can affect the statistical power of selection tests (Lotterhos \& Whitlock, 2015); thus, type I and type II errors are frequently associated with these approaches (Narum \& Hess, 2011). We minimized the potential for false discovery by identifying consensus candidate loci for selection among distinct methods used for two data sets: (a) the entire genotypic data set, including PA-arid individuals, using LOSITAN and PCADAPT consensus candidates and (b) a subset of genotypic data, which excluded the PA-arid samples due to absence of environmental data, using LOSITAN, PCADAPT and LEA consensus candidates (Figure S2).

\subsection{4 | Functional annotation of candidate loci putatively under natural selection}

A functional annotation of candidate loci was obtained by reciprocal nucleotide alignment between nextRAD sequences and the reference transcriptome, which was also characterized in the present study. BLAST + 2.2.31 (Camacho et al., 2009) was used with a threshold of at least 50 aligned nucleotides, a maximum of one mismatch and no gaps (Figure S2).

\section{4 | Transcriptomics}

\subsection{1 | Plant material for transcriptome assembly and differential expression analysis}

On August 16, 2013, three similarly sized A. germinans seedlings with 5-9 stem nodes were collected from the PA-arid and PAhumid sites, separated by the Bragança-Ajuruteua road, and transplanted with the surrounding soil into $3.0 \mathrm{~L}$ pots (Figure $2 \mathrm{c}$ ). Based on previous observations of other Avicennia species (Almahasheer, Duarte, \& Irigoien, 2016; Duarte, Thampanya, Terrados, GeertzHansen, \& Fortes, 1999), we estimate that all samples were 3.5 to 11 months old. For acclimation in a homogeneous environment, pots were placed in open-air and naturally shaded conditions and were watered daily with $300 \mathrm{ml}$ of tap water after sunset. Plants were harvested at noon, after $72 \mathrm{hr}$ of acclimation; washed with water; and split into roots, stems and leaves with a sterile blade to be stored in RNAlater (Ambion Inc.) and transported to the laboratory for RNA extraction. 


\subsection{2 | RNA extraction, cDNA library preparation and RNA sequencing}

RNA extraction was performed according to Oliveira, Viana, Reátegui, and Vincentz (2015). To assess purity, integrity and concentration, we used $1 \%$ agarose gel electrophoresis and a NanoVue spectrophotometer (GE Healthcare Life Sciences). Subsequently, cDNA-enriched libraries were constructed using TruSeq RNA sample preparation kits (Illumina Inc.). Library qualities were assessed using an AGILENT 2100 Bioanalyzer (Agilent Technologies), and concentrations were quantified using quantitative real-time PCR (qPCR) with a Sequencing Library qPCR Quantification kit (Illumina Inc.). Sequencing was performed with two 36-cycle TruSeq SBS pairedend kits (Illumina Inc.) on a Genome Analyzer Ilx platform (Illumina Inc.).

\subsection{3 | Transcriptome assembly and functional annotation of transcripts}

Raw data were filtered by quality using Phred $>20$ for $70 \%$ of the read length, and adapters were trimmed using NGS QC Toolkit 2.3 (Patel \& Jain, 2012). Filtered reads were de novo assembled into transcripts using the CLC Genomics Workbench (https://www.qiage nbioinformatics.com/). The distance between paired-end reads was set to 300-500 bp, the k-mer size was set to $45 \mathrm{bp}$, and the remaining default parameters were not changed.

Reads were mapped to the transcriptome using Bowtie1 (Langmead, Trapnell, Pop, \& Salzberg, 2009), and contiguous sequences (contigs) without read-mapping support were removed from the assembly. For transcript annotation, we used BLAST + 2.2.31 (Camacho et al., 2009) with an e-value < 1e-10, using reference sequences from manually curated databases as the National Center for Biotechnology Information (NCBI) RefSeq protein and RefSeq RNA (O'Leary et al., 2016) and representative proteins and cDNA from The Arabidopsis Information Resource (TAIR; Berardini et al., 2015). We removed putative contaminant contigs from the assembly, which did not match plant sequences but showed high similarity to nonplant sequences from the NCBI's RefSeq database. Sequences were assigned to the Kyoto Encyclopedia of Genes and Genomes (KEGG) orthology (KO) identifiers using the KEGG Automatic Annotation Server (Moriya, Itoh, Okuda, Yoshizawa, \& Kanehisa, 2007). Protein family domains were searched using the Pfam database and the HMMER3 alignment tool (Finn et al., 2014).

We identified putative open reading frames (ORFs) using the program TRANSDECODER (http://transdecoder.sf.net) with default parameters. Redundant transcripts were detected using CD-HIT-EST 4.6.1 ( $\mathrm{Li}$ \& Godzik, 2006) in the local alignment mode, with 95\% identity and $70 \%$ coverage of the shortest sequence thresholds. To minimize redundancy, in the final assembly, we retained only sequences with the longest putative ORF and the longest putative noncoding transcripts from each CD-HIT-EST cluster. Functional categories were assigned to putative coding sequences using the Arabidopsis thaliana association file from the Gene Ontology Consortium website (Blake et al., 2015; Figure S2).

\subsubsection{Analysis of differentially expressed transcripts (DET)}

Counts of reads mapped to assembled transcripts per sequenced sample were used as input files in DET analyses. Reads that mapped to multiple transcripts were excluded. The count matrix was normalized and used to detect transcripts with significant differential expression between PA-arid and PA-humid samples from the Bragança-Ajuruteua road (Figure 2) with the EdgeR Bioconductor package (Robinson, McCarthy, \& Smyth, 2010) at an FDR $<0.05$. Gene Ontology (GO) term enrichment analyses were performed using the goseq $\mathrm{R}$ Bioconductor package, which takes the length bias into account, with the default approximation method and a $p$ value cutoff set to <.05 (Young, Wakefield, Smyth, \& Oshlack, 2010; Figure S2).

\section{3 | RESULTS}

\subsection{Population genetics analyses of Avicennia germinans along the equatorial coast of Brazil}

Genetic diversity indices are shown in Table 2. The lowest levels of genetic variation were observed at the TMD site. The remaining sites, influenced by the northern branch of the SEC, presented considerably higher levels of diversity, including the PA-arid site, which was one of the most genetically diverse across the study region. All sampling sites deviated from Hardy-Weinberg equilibrium (HWE), with an excess of heterozygosity in all sites, except for ALC, which showed a small heterozygosity deficit (FIS $=0.03$ ). HWE deviation was highest in TMD (FIS $=-0.43$ ) but relatively low at all remaining sites, ranging from -0.15 (PNB) to +0.03 (ALC).

A substantial genetic structure was observed over the Equatorial Brazilian coast (Figure 3). The genetic diversity, based on 2,297 genome-wide SNPs genotyped in 57 individuals, was organized into four distinct genetic clusters $(K=4$; Figure $3 a$ and $\mathrm{S} 3 \mathrm{a}-\mathrm{b}$ ). The greatest genetic divergences (FST > 0.46; Nei's distance $>0.255$ ) were observed between individuals from TMD and those from all other sites (Figure 3b-c; Table S1). The TMD site also presented the highest pA (46). Most remarkable was the divergence between individuals from PA-arid and its adjacent site PA-humid (FST $=0.25$; Nei's distance $=0.181$ ). This divergence was even greater than the observed divergence of PA-arid from PRC individuals (Table S1), located approximately $900 \mathrm{~km}$ from each other (FST $=0.23$; Nei's distance $=0.177$ ) on the semiarid coast of Brazil. The divergent gene pool of the PA-arid population was also evident when these samples were excluded from structure analyses. The most likely number of ancestral populations dropped from four to 
TABLE 2 Genetic diversity statistics, based on analyses of 2,297 genome-wide polymorphic loci detected in 57 individuals sampled in seven sampling sites along the equatorial Atlantic coastline of South America

\begin{tabular}{|c|c|c|c|c|c|c|c|c|c|}
\hline Sampling site & $\pi$ (mean) & $\pi(S E)$ & $H_{\mathrm{E}}$ & $H_{\mathrm{O}}$ & $\mathrm{pA}$ & \%Poly & FIS & $\begin{array}{l}\text { Low level } \\
(95 \% \mathrm{Cl})\end{array}$ & $\begin{array}{l}\text { High level } \\
(95 \% \mathrm{CI})\end{array}$ \\
\hline MRJ & 0.264 & 0.206 & 0.244 & 0.292 & 1 & 72.70 & -0.136 & -0.154 & -0.102 \\
\hline PA-humid & 0.301 & 0.186 & 0.280 & 0.328 & 0 & 84.46 & -0.113 & -0.132 & -0.084 \\
\hline ALC & 0.282 & 0.214 & 0.249 & 0.269 & 0 & 69.83 & 0.030 & 0.009 & 0.070 \\
\hline PRC & 0.323 & 0.193 & 0.296 & 0.327 & 1 & 82.15 & -0.035 & -0.053 & -0.002 \\
\hline TMD & 0.123 & 0.192 & 0.130 & 0.168 & 46 & 34.52 & -0.426 & -0.452 & -0.376 \\
\hline
\end{tabular}

Abbreviations: $\pi$, nucleotide diversity; $H_{\mathrm{E}}$, expected heterozygosity; $H_{\mathrm{O}}$, observed heterozygosity; pA, private alleles; \%Poly, percentage of polymorphic loci; FIS, inbreeding coefficient.

three (Figure 3c-d and S3c-d), and the overall structure remained unchanged (Figure 3d). At a finer scale, individuals from the PAhumid and MRJ sites on the AMMC seemed to be derived from the same ancestral population. This population, in turn, diverged from the population that may have given rise to individuals from the ALC, PNB, and PRC sites in Northeast Brazil (Figure 3a-b).

\section{2 | De novo assembly and annotation of the Avicennia germinans reference transcriptome}

We used RNA-Seq to sequence and de novo assemble a reference transcriptome from the leaves, stems and roots of A. germinans seedlings to provide a functional context for this study. A total of 249,875,572 high-quality-filtered, paired-end, 72 bp reads representing $78.25 \%$ of the raw data were used in the assembly. The reference transcriptome comprised 47,821 contigs after removing misassembled, redundant and contaminant sequences. Putative ORFs were identified in 29,854 contigs and subsequently annotated as putative protein-coding transcripts. The remaining 17,967 contigs were classified as putative noncoding transcripts. A detailed characterization of contigs can be found in Table S2.

Raw reads were mapped back to the reference transcriptome, with over $82 \%$ uniquely mapped to a single transcript and only $1.31 \%$ mapped to more than one transcript (Table S3). We found $91.74 \%$ of the plant universal orthologs from the Busco database (Simão, Waterhouse, loannidis, Kriventseva, \& Zdobnov, 2015) represented in the reference transcriptome (Table S3). We also found from 20,529 to 31,348 putative orthologous sequences between the $A$. germinans transcriptome and four other publicly available transcriptomes derived from the genus Avicennia L. (Acanthaceae; Table S4).

As expected, most putative protein-coding transcripts of the reference transcriptome could be annotated using relevant databases (92.6\%), whereas only a few putative noncoding transcripts could be annotated (33.6\%; Figure S4). We found 2,207 putative coding transcripts $(7.4 \%)$ and 11,925 putative noncoding transcripts (66.4\%) unique to $A$. germinans, which may represent lineage-specific sequences.

\section{3 | Detection of candidate loci responding to environmental selection}

Genome-wide signatures of selection were detected from genotypic data retrieved from samples from all seven sites of collection. A total of 56 putative outlier loci were consistently identified by two FST outlier methods, solely based on deviations from neutral expectations of the distribution of genetic diversity. Eleven of these loci aligned to sequences in the reference transcriptome, of which eight were highly similar to proteins associated with the response or tolerance to drought in A. thaliana or Sesamum indicum (Figures $4 \mathrm{a}$ and $\mathrm{S5}$ ).

The exclusion of PA-arid samples was necessary for G-E association tests due to limitations in the resolution of MARSPEC and WORLDCLIM environmental layers. From the remaining subset of 48 individuals from six sampling sites, 153 candidate loci for selection were identified by G-E correlation and two FST outlier approaches (Figure 4b). Of these candidate loci, 24 aligned to the reference transcriptome, of which 20 were putative protein-coding showing high similarity to gene models from A. thaliana or S. indicum (Figure S5).

Among all candidate loci for selection detected along the sampling region, we found 14 loci associated with plant growth and development, wood formation, cell wall metabolism, biogenesis of the photosynthetic apparatus, abiotic stress perception and response and protein protection from stress-induced aggregation, among other processes (Table 3; Figure 4a).

\subsection{Differential transcript expression analysis}

Transcriptome sequencing of seedlings grown under contrasting field conditions revealed significant expression differences in 2,454 transcripts, despite previous acclimatization under homogeneous shaded, well-watered conditions (Figure 2c). Most DETs were detected in roots $(2,337)$ and stems $(1,383)$, followed by leaves $(361$; Figures 5 and S6). We refer to DETs that showed higher expression levels in samples from the PA-arid site than in samples from the PAhumid site as "DET-Arid" and to DETs showing a significantly higher 
(a)

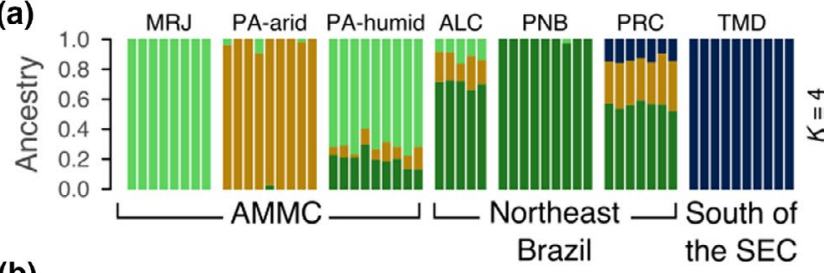

(b)

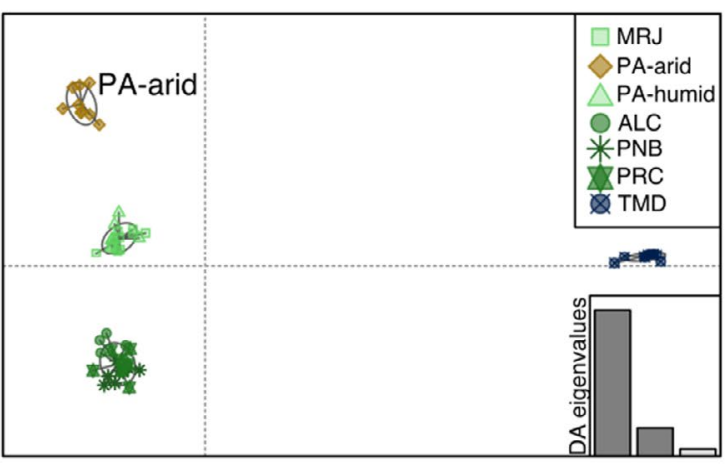

(c)

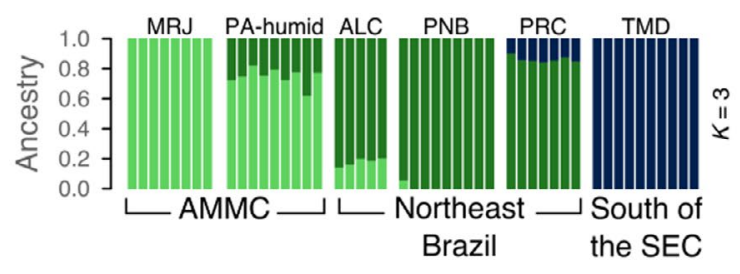

(d)

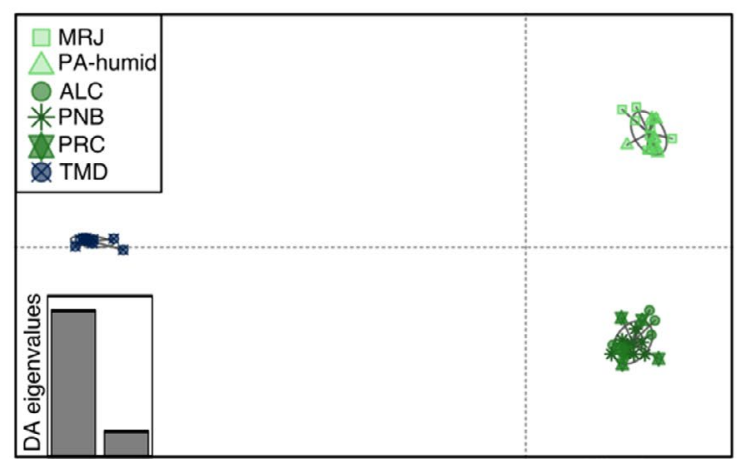

FIGURE 3 Genetic structure inferred from genome-wide single nucleotide polymorphisms (SNPs) detected in Avicennia germinans. (a) Attribution of ancestry implemented in the program ADMIXTURE 1.3.0 for all sampled individuals; stacked bars represent individuals, and each colour represents one ancestral cluster $(K=4)$. (b) Scatterplot of the first two principal components of the multivariate discriminant analysis of principal components (DAPC) of total genetic variance; all sampled individuals are represented as points; distinct symbols indicate sampling sites. (c) Attribution of ancestry (using ADMIXTURE 1.3.0) for all sampled individuals, excluding PA-arid samples; stacked bars represent individuals, and each colour represents one ancestral cluster $(K=3)$. (d) Scatterplot of the first two principal components of the DAPC of total genetic variance; sampled individuals, except for individuals sampled in the PA-arid site, are represented as points; and distinct symbols indicate sampling sites [Colour figure can be viewed at wileyonlinelibrary.com]

expression in samples from the PA-humid than in samples from the PA-arid site as "DET-Humid".

The functional annotation and subsequent assignment of most putative protein-coding transcripts to GO terms (76.24\%; Figure
S4) enabled the assessment of DETs that highlighted key aspects of a differential response of $A$. germinans to contrasting source environments, differing markedly in hydrological regime, soil pore water salinity, solar radiation and surface temperature (Lara \& Cohen, 2006; Pranchai et al., 2017; Vogt et al., 2014). We focused this analysis on enriched biological processes previously identified to be involved in the tolerance, resistance or response to osmotic and drought stress in various crops, model and nonmodel species, including mangroves (Figure 5). A detailed characterization of the differentially expressed transcripts belonging to such processes is shown in Table S5. In the following subsections, we summarize these results.

\subsection{1 | Photosynthesis}

Differential transcript expression analyses revealed that photosynthesis-associated transcripts were enriched, mainly in the roots and stems from the DET-Arid set. These included putative enzymes and genes required for chloroplast biogenesis or development, for chlorophyll biosynthesis, and for the assembly of the photosynthetic apparatus and light-harvesting complexes and those involved in acclimation to fluctuating light. The DET-Arid set of root samples also presented transcripts associated with the $\mathrm{C} 3$ carbon fixation pathway, including glyceraldehyde-3-phosphate dehydrogenase subunits, Calvin cycle proteins, and Ribulose bisphosphate carboxylase small chain $1 \mathrm{~A}$ (RBCS1A), which showed a 7.8-fold change relative to the roots of PA-humid samples.

\subsection{2 | Response to light}

The DET-Arid sets of roots and stems were enriched in transcripts associated with the response to light but not directly associated with photosynthesis. These included transcripts similar to genes and transcription factors involved with light acclimation and essential for maintaining electron flow and photosynthetic efficiency under changing light conditions (Privat, Hakimi, Buhot, Favory, \& LerbsMache, 2003). The DET-Arid sets of roots and stems also included putative light-signalling genes and photoreceptors such as phototropins, cryptochromes and phytochromes. These photoreceptors are sensitive to light intensity and control complex light and stress responses, including photoinduced movements as well as growth and development under limiting light (Correll et al., 2003; Ohgishi, Saji, Okada, \& Sakai, 2004; Pedmale et al., 2016). Complementarily, we identified transcripts similar to proteins that interact with these photoreceptors in the mediation of shade avoidance and phototropism under low light and to low-light-induced transcription factors, which regulate developmental processes and growth in response to shade avoidance. Moreover, in the DET-Arid sets of roots and stems, we found transcripts associated with chloroplast accumulation upon low blue light and with the response to sugar starvation induced by dark. 
(a)

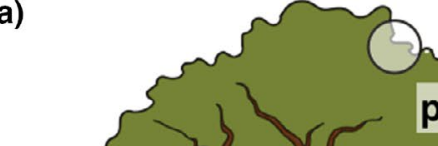

Biogenesis of the photosynthetic apparatus

Wood formation MAP70-5 \$ $\mathrm{NAC073}$
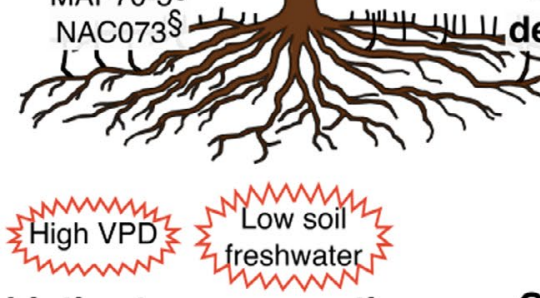

Abiotic stress perception and response KEGII HSL1 1 LRR RLK§ DNAJST
TPR $\$$ II OBGC\$ञ TPR 2 domain

Growth and evelopment KEG" OPF7\$T OBGC\$币 MAP70-5§

Cell wall metabolism

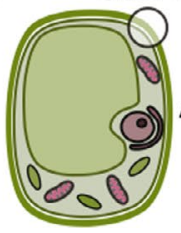

MEE23I

GLCAK"

AT1G09910\$I

MAP70-5 $\$$

NAC073§ (b)

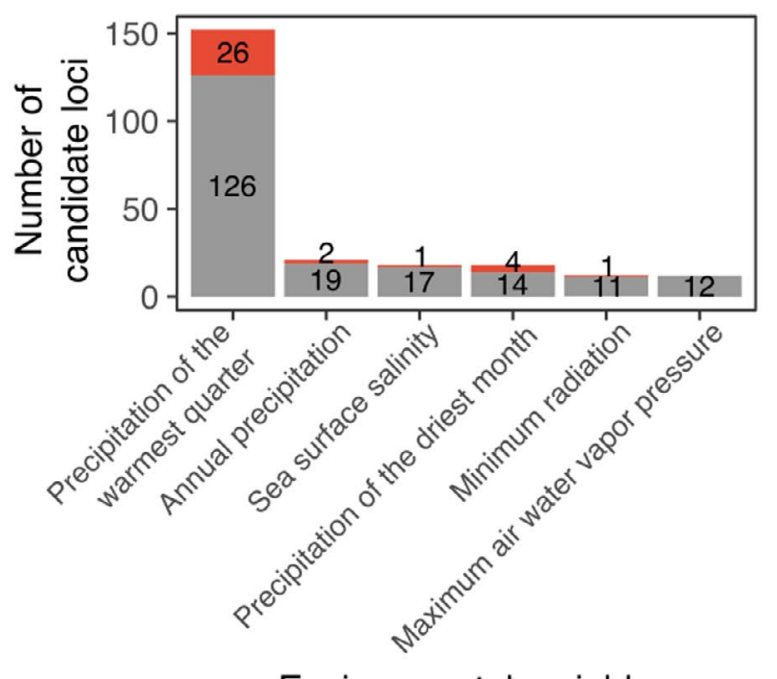

\section{Environmental variable}

G-E association +

$\mathrm{F}_{\mathrm{ST}}$ outlier methods

G-E association only

FIGURE 4 Candidate loci for selection detected from Avicennia germinans sampled along tropical mangrove forests of the northnortheastern Brazilian coast. (a) Schematic representation of key biological processes associated with candidate loci. Arabidopsis thaliana gene symbols listed below biological processes represent the functional annotation of candidate loci present within putative proteincoding regions of the genome. §Labelled gene symbols, candidates obtained using FST outlier tests performed with all sampled individuals, including PA-arid samples. TLabelled gene symbols, candidates obtained by combining genetic-environmental association tests and FST outlier approaches, using a subset of samples, without PA-arid ones, for which environmental characterization could not be retrieved from public databases. (b) Number of candidate SNPs associated with noncollinear environmental variables [Colour figure can be viewed at wileyonlinelibrary.com]

\subsection{3 | Response to water deprivation and response to salt}

The DET-Arid sets of roots and stems were also enriched in transcripts associated with the response to osmotic stress and water deprivation, including putative genes that play relevant roles in drought and salt stress resistance. For instance, we found transcripts associated with abscisic acid (ABA)-dependent stomatal closure, a well-known mechanism for maintaining water status under drought, which severely compromises growth (Murata, Mori, \& Munemasa, 2015). Additionally, the DET-Arid sets of roots and stems included transcripts associated with drought-induced ion transporters, which protect chloroplasts from deleterious $\mathrm{Na}^{+}$concentrations (Müller et al., 2014) and are involved in $\mathrm{Ca}^{2+}$ homeostasis under abiotic stress. Complementarily, we found in the DET-Arid sets of roots and stems transcripts associated with biosynthesis and accumulation of oligosaccharides, which may act as osmoprotectants, increasing tolerance to osmotic stress (ElSayed, Rafudeen, \& Golldack, 2014; Nishizawa, Yabuta, \& Shigeoka, 2008; Taji et al., 2002). Additionally, transcripts associated with drought-induced epicuticular wax biosynthesis, transport and deposition in cell walls were among DETArid sets of roots and stems. We also detected in these sets of DETs several transcripts associated with reactive oxygen species dissipation for the control of cell damage caused by drought, high light or salt stress, including copper/zinc superoxide dismutases, a chloroplastic drought-induced stress protein (CDSP32) and MAP KINASE 6 (MAPK6).

\subsubsection{Response to heat}

Transcripts similar to genes that confer tolerance to heat were enriched among the DET-Arid sets of roots and stems. We detected several putative cochaperones and chaperones, which protect proteins from structural degradation (Al-Whaibi, 2011), and transcripts associated with putative components of thermomemory, required for long-term maintenance of acquired thermotolerance (Charng et al., 2006).

\subsection{5 | Photorespiration}

In the DET-Arid set of roots, we detected an enrichment of putative genes associated with photorespiration, similar to enzymes participating in transamination, required for maintaining photosynthesis under photorespiratory conditions and for carbon flow during photorespiration and which catalyze the concluding reaction of photorespiration. 


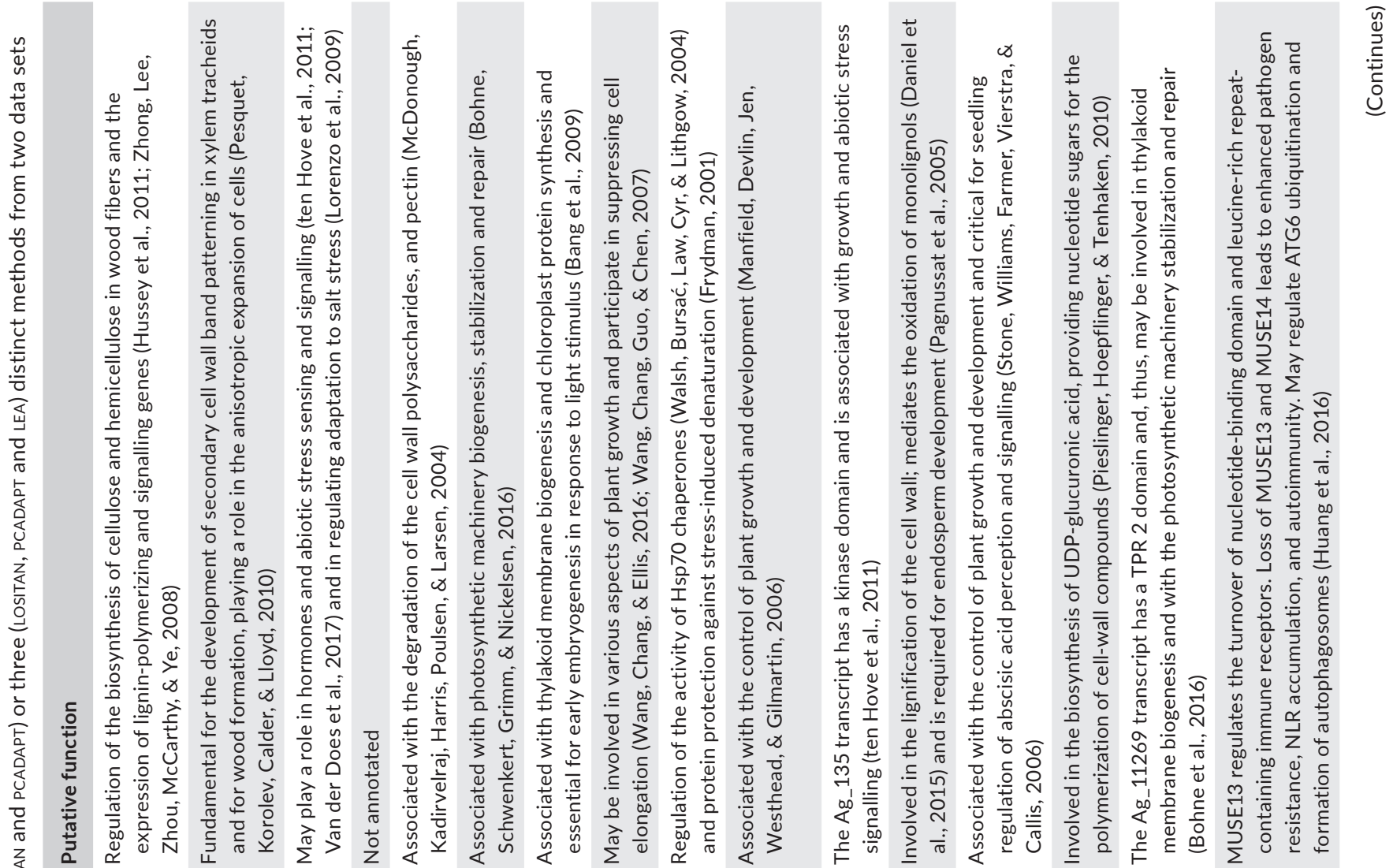

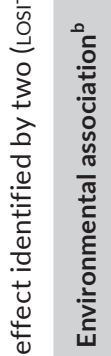
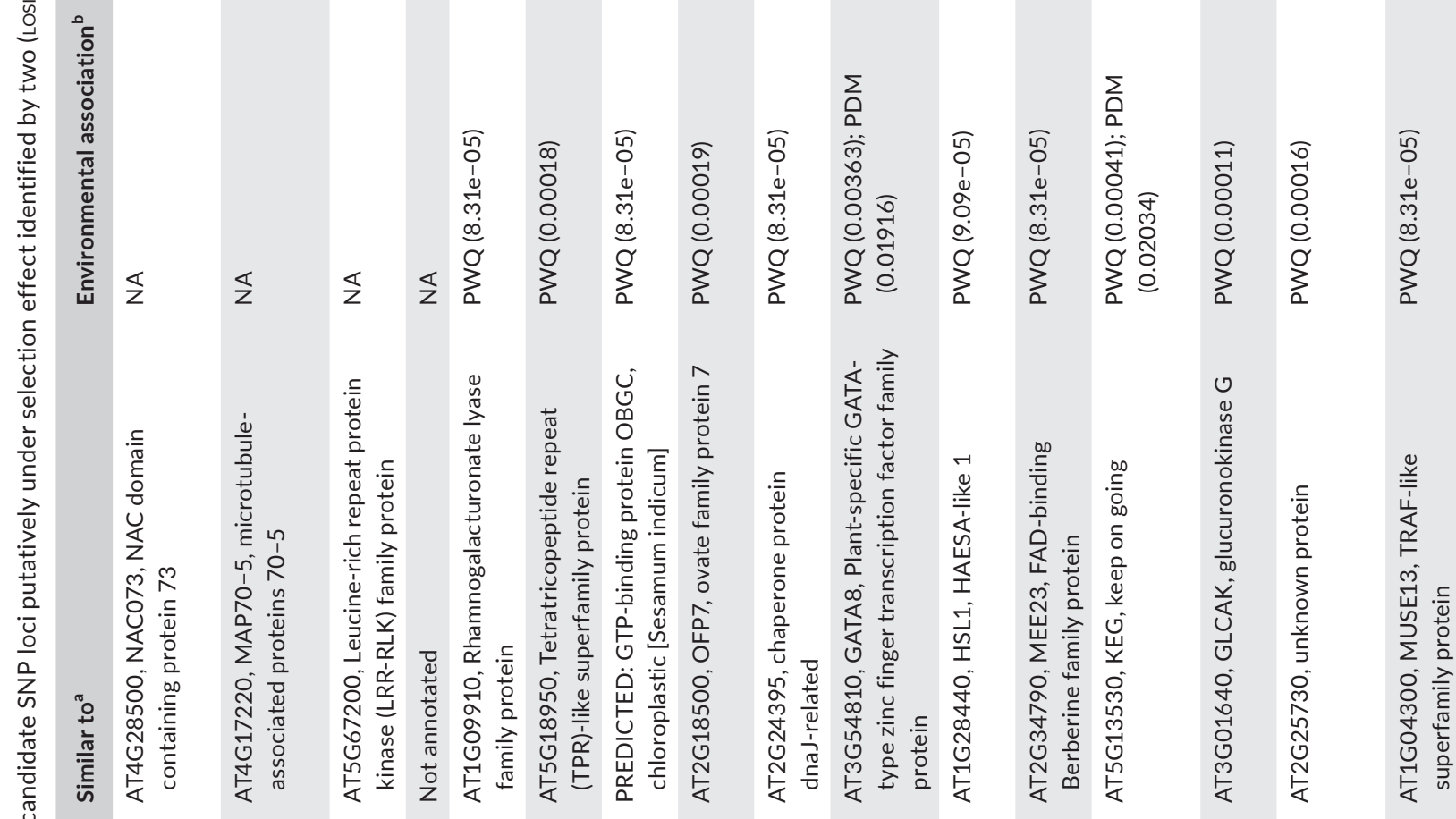

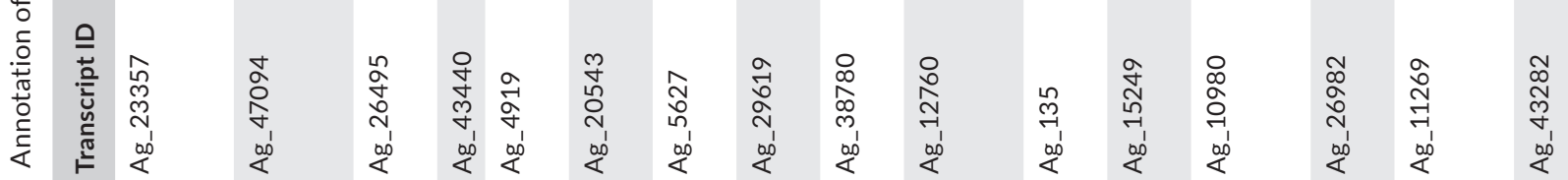

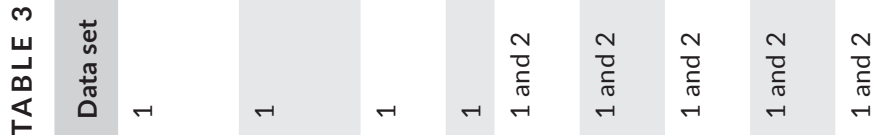




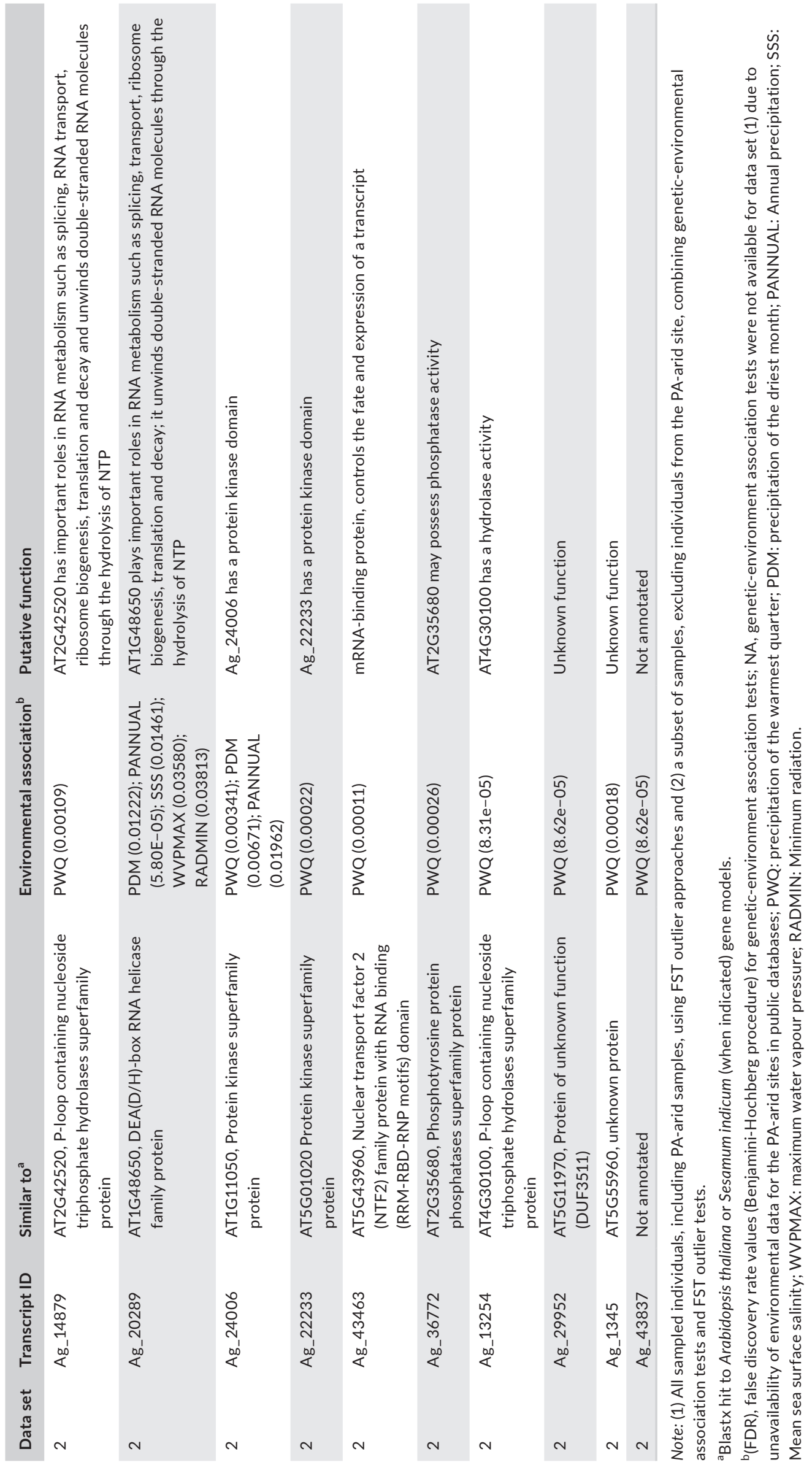


FIGURE 5 Functional categories of differentially expressed transcripts (DETs) identified between samples grown in the PA-arid and PA-humid sampling sites. Categories were selected based on biological processes previously identified to be involved in the response, acclimation or resistance to water stress in model plants [Colour figure can be viewed at wileyonlinelibrary.com]

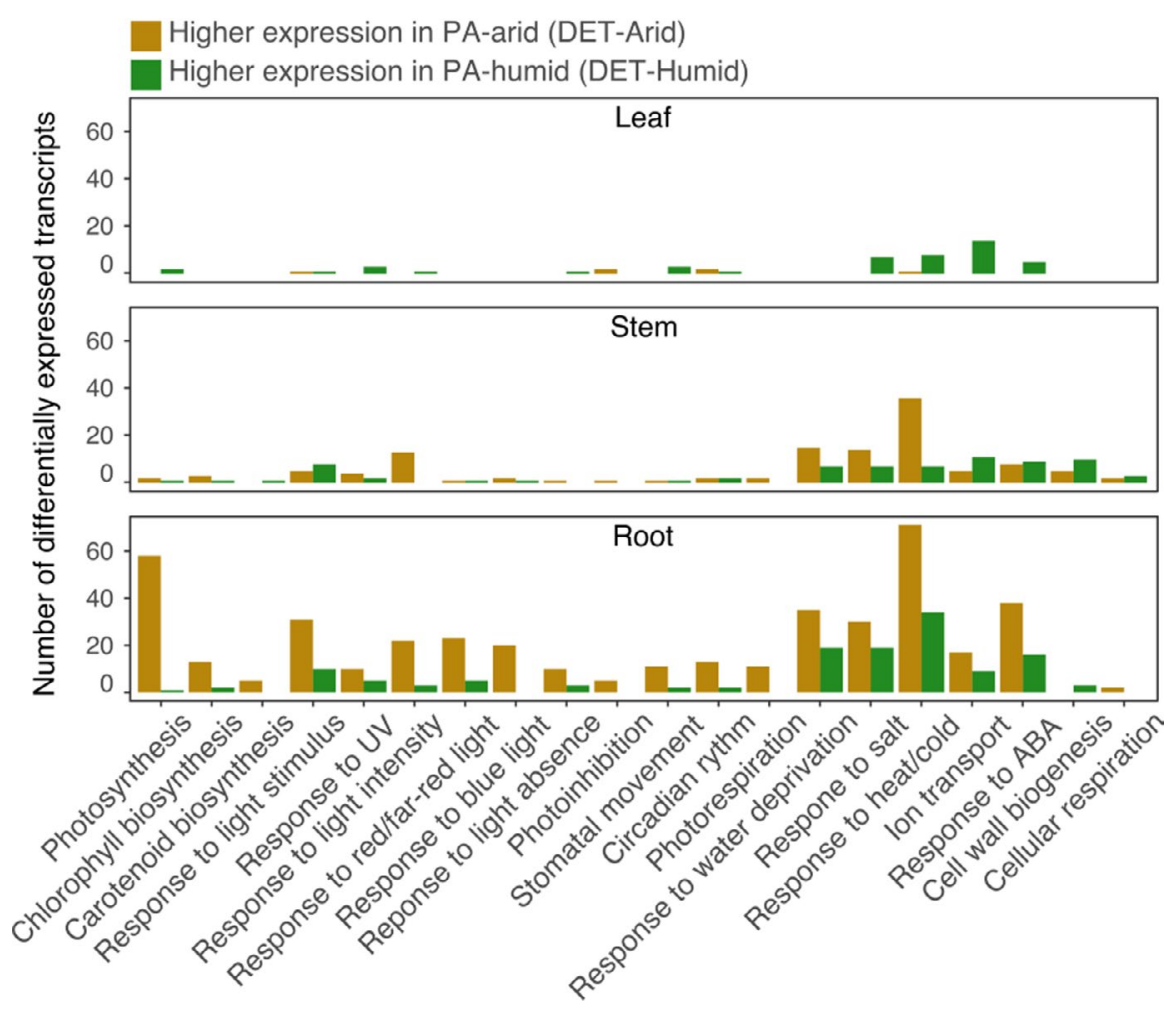

\section{4 | DISCUSSION}

Our study suggests that spatial variation in freshwater availability plays an important role in driving adaptation of the typically tropical and widespread tree Avicennia germinans. In the following subsections, we describe how variation in oceanographic and bioclimatic variables along the equatorial Brazilian coast seem to influence the organization of genome-wide genetic diversity of the species. Moreover, we show that drastic and persistent restriction in soil freshwater availability probably caused the rapid evolution of the phenotype, gene pool and gene expression profile of a recently founded population of $A$. germinans, without depletion of genetic diversity and despite the clear possibility of gene flow with an adjacent, unchanged population.

\section{1 | Gradual environmental variation in freshwater availability may partly explain the organization of non-neutral genetic variation in A. germinans}

The genetic structure inferred by genome-wide SNPs (Figure 3) suggested the importance of both neutral and nonneutral environmental drivers of variation. The greatest divergence was observed between samples influenced by the northern and southern branches of the South Equatorial sea current (SEC; Figure 1) acting on the Atlantic coast of South America, corroborating previous results found for other coastal trees using putatively neutral molecular markers (Francisco, Mori, Alves, Tambarussi, \& de Souza, 2018; Mori, Zucchi, Sampaio, et al., 2015; Takayama, Tateishi, Murata, \& Kajita, 2008). The flow direction of coastal currents provides a neutral explanation for the structure of genome-wide diversity of sea-dispersed species due to restrictions in the dispersal of buoyant propagules, probably facilitating the accumulation of random genetic divergences (Francisco et al., 2018; Mori, Zucchi, \& Souza, 2015; Wee et al., 2014; Yan, Duke, $\&$ Sun, 2016). Our results also suggest that the lower precipitation of the warmest quarter in northern sites (AMMC and Northeast Brazil regions; Figure 1) may play an additional, nonneutral role in shaping this north-south divergence. We hypothesize that the more even distribution of rainfall throughout the year in the TMD site probably alleviates water stress in A. germinans, whereas limited rainfall in the warmest quarter of northern regions increases soil aridity and salinity, reducing opportunities for rehydration and potentially favouring increased drought tolerance. It is plausible that this environmental filter contributes to the genetic divergence observed between TMD and remaining populations (Figure 3 ). This hypothesis is corroborated by the detection of 26 loci candidate for selection correlated to the spatial variation in the precipitation of the warmest quarter over the study area (Figure 4b). Although most of these loci were poorly characterized, hampering inferences about their functional relevance in the environmental context, we were able to associate 11 candidates with biological processes influenced by drought, such as photosynthesis, cell wall metabolism, cell elongation, plant growth, protein protection from stress-induced degradation and regulation of $A B A$ signalling (Table 3; Figure 4). The adaptive importance of freshwater limitation in tropical trees was also suggested in the mangrove A. schaueriana (Cruz et al., 2019) and in tropical forests and savannas (Ciemer et al., 2019), for which it was similarly suggested that an environmental filtering mechanism driven by rainfall variability probably favoured the survival of more drought resistant lineages. 
Although Avicennia propagules can remain viable for long periods and present transoceanic dispersal (Mori, Zucchi, Sampaio, et al., 2015), at a finer scale, we observed a genetic divergence between sites in the AMMC region (MRJ and PA-humid) and Northeast Brazilian mangroves (ALC, PNB and PRC; Figure 3). The AMMC region shows higher annual precipitation and is more strongly influenced by riverine freshwater inputs than the remaining sites due to its closer proximity to the Amazon River Delta (Figure 1). Conversely, the northeast Brazilian coastline is characterized by reduced rainfall and the lack of riverine freshwater inputs (Figure 1), which limit plant access to soil freshwater due to increased salinity, potentially contributing to the local specialization of individuals. In fact, we were able to detect two loci associated with sea surface salinity data and total annual precipitation based on both FST outlier methods and G-E association tests (Figure 4b). These loci showed similarity to a poorly characterized protein kinase and to an RNA hydrolase (Table 3). Given the unclear functional relevance of these putative adaptive loci in the environmental context, we recommend future efforts to analyze the role of demographic history in A. germinans to find additional explanations for the genetic structure observed along the equatorial Brazilian coastline (Figure 3). Additionally, candidate loci detected in our study may play a role in drought adaptation, but their molecular functions need to be further characterized in plants adapted to physiological drought. The functional role of these proteins in drought tolerance may not be highlighted in genetic screenings performed on drought-sensitive model plants distantly related to $A$. germinans.

\subsection{Rapid evolution of A. germinans in response to abrupt limitation in access to soil freshwater}

The PA-arid population of A. germinans originated after 1974, when the construction of the Bragança-Ajuruteua road altered the hydrology of part of the mangrove forest in the AMMC region (Figure $2 a-b$; Cohen \& Lara, 2003). This sudden environmental change caused a large dieback of the mangrove vegetation, followed by a gradual recolonization, mainly by A. germinans. We estimate that the time since this event occurred could represent at most 40 reproductive cycles of $A$. germinans, based on previous observations of closely related Avicennia spp. (Almahasheer et al., 2016; Cruz et al., 2019), although a conservative estimate could be four generations (Polidoro et al., 2010). The modification of the architecture of recolonizing individuals of PA-arid, from the previous tall/arboreal to the now dwarf/ shrub (Figure 2b; Pranchai et al., 2017), suggests that limitation in plant access to soil water favoured smaller tree sizes, one of the most integrative characteristics of drought resistance (Bennett et al., 2015; Corlett, 2016; Rowland et al., 2015). We could not determine how much of the observed difference in tree size is inherited or determined by phenotypic plasticity; however, our results revealed a substantial change in genome-wide allele frequencies of trees, which probably represent samples of the first generations of the recolonizing population (Table 2; Figure 3a). Interestingly, changes in allele frequencies at founding occurred without reductions in levels of diversity, as estimated by various population genetics parameters (Table 2). Moreover, consistent with an adaptive response to selection and probably driven by restrictions in plant access to soil freshwater, FST outlier tests detected 56 candidate loci, of which eight were present within transcripts associated with functions such as suppression of cell elongation, wood and xylem tracheid formation, photosynthetic machinery biogenesis and repair, regulation of adaptation to stress and protection from stress-induced protein degradation (Table 3; Figure 4a). The simultaneous presence of high levels of diversity in the founding population (Table 2 ) and strong selection of individual traits is common in natural populations and represents a signature of substantial multivariate genetic constraints (Walsh \& Blows, 2009), as expected in this specific case given the magnitude of environmental change.

A surprising aspect of the population genetic analyses, however, was that genome-wide changes in allele frequencies occurred despite expectations of high levels of gene flow, given the proximity ( $<10.0 \mathrm{~m}$ ) of contrasting populations and characteristics of the species, which is preferably allogamous, with entomophilous flowers (Mori, Zucchi, \& Souza, 2015; Nadia et al., 2013; Nettel-Hernanz et al., 2013). In the absence of a geographic barrier to gene flow, recombination is expected to hinder adaptation unless there is very strong selection or reproductive isolation (Kawecki \& Ebert, 2004; Mayr, 1963). As we expect selection to be very strong in this case, due to extreme environmental change, it could be enough to counteract the homogenizing effect of gene flow or even to cause shifts in the timing of flowering (Cho, Yoon, \& An, 2017), which may result in reproductive isolation.

In addition to genetic changes, we also identified transcript expression differences between seedlings from PA-arid and PA-humid sites after acclimatization in pots under shaded, well-watered conditions (Figures $2 \mathrm{c}$ and 5 ), indicating an additional molecular basis for phenotypic divergences. Because differential gene expression influences trait variation (Wolf, Lindell, \& Backstrom, 2010), it can be substantial between distinct locally adapted populations (Akman, Carlson, Holsinger, \& Latimer, 2016; Gould, Chen, \& Lowry, 2018). Differential expression was observed mainly in the roots and stems of $A$. germinans seedlings and was functionally associated with differences in freshwater availability between source sites. Mangrove roots are the first organs exposed to increased salinity and water deficits; thus, osmotic stress sensing and signalling to the whole plant are triggered (Chaves, Maroco, \& Pereira, 2003; Janiak, Kwaśniewski, \& Szarejko, 2016). Moreover, these roots are photosynthesizing, contributing to carbon gain and enabling respiration in anaerobic soils, using both atmospheric and photosynthetically regenerated oxygen (Kitaya et al., 2002). Interestingly, functional categories associated with the detected transcriptome changes in PA-arid seedlings included various biological processes previously identified to be involved in central aspects of osmotic, heat and UV stress in model and nonmodel plants (Ding et al., 2013; Fan et al., 2018; Zhang et al., 2015). Being sessile under extreme environmental conditions, PA-arid plants should need to rapidly adjust gene expression to intermittent freshwater availability (Chaves, Flexas, \& 
Pinheiro, 2009; Urban, Aarrouf, \& Bidel, 2017). Thus, the increased freshwater supply and the restriction in solar irradiance, to which samples from the degraded PA-arid site were subject under the experimental conditions (Figure 2c), probably required seedlings to broadly adjust their photosynthetic machinery. Conversely, although environmental conditions were relaxed in the RNA-Seq experiment, we observed several transcripts associated with high temperature, drought and salinity response among DET-Arid, including photorespiration, epicuticular wax and cutin synthesis, export and deposition, accumulation of osmoprotectants and antioxidants and ion homeostasis. By using a common garden to control the environmental variation during $72 \mathrm{hr}$ (Figure 2c), we maximized the chances of finding differences in gene expression caused by inheritable variations at the genetic or epigenetic levels in individuals from different source populations (Hatorangan, Laenen, Steige, Slotte, \& Köhler, 2016; Savolainen, Lascoux, \& Merilä, 2013). Although we cannot rule out that the observed gene expression differences were caused by epigenetic modifications acquired during germination or growth (i.e., before the experiment) or by maternal inheritance, we expect them to be at least partly inheritable. Thus, we suggest that these findings can potentially represent regulatory mechanisms by which PA-arid plants tolerate a predominantly warm, highly saline and dry environment with extreme UV levels. These strategies may have enhanced the relative capacity of PA-arid seedlings to grow under a high leaf water-deficit status and infrequent freshwater inputs.

We suggest that future efforts to understand the molecular mechanisms of adaptation of the PA-arid population should focus on characterizing epigenetic differences between the PA-arid and PA-humid sites. Epigenetic changes can emerge faster than adaptive genetic changes, also playing an important role in the early adaptive process (Kenkel \& Matz, 2016; Pavey, Nosil, \& Rogers, 2010). Although the mechanisms are not entirely clear, our results obtained through independent molecular approaches suggest that a rapid evolution of this population occurred with gene expression and genetic changes. The desertification of the PA-arid site represents a drastic and persistent environmental change, analogous to a freshwater exclusion experiment for mangroves of the tropical Brazilian coastline, in which this limitation probably caused the rapid evolution of recolonizing A. germinans individuals. Although it is difficult to demonstrate rapid evolution in nature, there is growing empirical evidence that when environmental selection is very intense, evolutionary processes may occur on a very fast time scale (Amorim et al., 2017; Donihue et al., 2018; Schoener, 2011), as observed in this case.

\section{3 | Implications for conservation}

Wetlands of the northeastern coast of Brazil and the ecosystem services they provide are predicted to be particularly impacted by future reductions in precipitation and freshwater availability (Osland et al., 2018). Despite these threats, the extant gene pool of northern populations of $A$. germinans seems to harbour sufficient diversity to enable species persistence through natural selection of droughtresistant plants, as observed in the case of PA-arid. Recolonizing individuals in this location share alleles with individuals from distant areas, such as the PRC and ALC sites (Figure 3a) in Northeast Brazil, suggesting that these forests might have contributed as a source of adaptive variation through sea-dispersed propagules in the recolonization of the PA-arid site in addition to the selection of migrants from adjacent areas.

In the context of an increasingly drying climate, reforestation plans for populations of $A$. germinans located south of the SEC should consider using mixed stocks of seedlings (Moritz, 1999) to introduce genetic variation associated with increased drought tolerance present in Northeastern mangroves while also maintaining local alleles, possibly associated with site-specific environmental characteristics.

In conclusion, we provide novel insights into how limited access to soil freshwater can change allele frequencies, gene expression and phenotypes of a dominant tropical tree. These findings are consistent with the predictions of a hypothesis of natural selection, although we acknowledge that other evolutionary processes could also play a role in driving the observed patterns, opening new opportunities for future investigation. Research on the genomic basis of tree adaptation is often limited by difficulties in implementing empirical tests, given their long generation time and the scarcity of basic biological information. In tropical forests, mostly found in developing countries, the lack of resources imposes additional challenges for adaptation studies. Advances in the understanding of the genomic basis of drought tolerance in tropical trees can support effective protection plans and mitigate climate change. As shown in this study, such knowledge can improve predictions of the persistence of the ecosystems they form and services they provide and generate key insight for conservation and management efforts (Holliday et al., 2017; Moran, Hartig, \& Bell, 2016).

\section{ACKNOWLEDGEMENTS}

We acknowledge Ilmarina Menezes for assistance with fieldwork and HPC services at Louisiana State University. M.V.C. received fellowships from the São Paulo Research Foundation - FAPESP (PhD 2013/26793-7) and from the Coordination for the Improvement of Higher Education Personnel - CAPES Computational Biology Program (PhD SWE 8084/2015-07, PhD 88887.177158/2018-00). G.M.M. received fellowships from FAPESP (PD 2013/08086-1, PD BEPE 2014/22821-9) and a grant from the Brazilian National Council for Scientific and Technological Development - CNPq (PD 448286/2014-9). M.D. and D-H.O. received grants from the United States National Science Foundation award (MCB 1616827) and the Next-Generation BioGreen21 Program of the Rural Development Administration, Republic of Korea (PJ01317301). R.S.O. received a CNPq research scholarship and a grant from Microsoft researchFAPESP (2011/52072-0). A.P.S. received a grant from CAPES Computational Biology Program (88882.160095/2013-01) and, a research fellowship from CNPq (309661/2014-5). 


\section{AUTHOR CONTRIBUTIONS}

A.P.S., G.M.M. and M.V.C. designed the study. M.V.C. and G.M.M. conducted fieldwork, prepared samples for sequencing and wrote the manuscript. M.V.C., G.M.M., R.S.O., M.D. and D.H.O. analyzed the RNA-Seq and nextRAD results. A.P.S., M.I.Z., and G.M.M. contributed material/reagents/analytical tools. All authors discussed the results and contributed to the manuscript.

\section{DATA AVAILABILITY STATEMENT}

Gene expression data and transcriptome sequences that support conclusions have been deposited in GenBank with the accession code GSE123659.

SNP genotypes are available at Dryad https://doi.org/10.5061/ dryad.pk0p2nghr (Cruz et al., 2019).

\section{ORCID}

Mariana Vargas Cruz iD https://orcid.org/0000-0001-8569-2234 Gustavo Maruyama Mori (iD https://orcid.

org/0000-0003-2308-2224

Dong-Ha Oh iD https://orcid.org/0000-0003-1526-9814

Maheshi Dassanayake iD https://orcid.org/0000-0003-3123-3731

Maria Imaculada Zucchi iD https://orcid.

org/0000-0002-4863-1843

Rafael Silva Oliveira iD https://orcid.org/0000-0002-6392-2526

Anete Pereira de Souza (D) https://orcid.org/0000-0003-3831-9829

\section{REFERENCES}

Akman, M., Carlson, J. E., Holsinger, K. E., \& Latimer, A. M. (2016). Transcriptome sequencing reveals population differentiation in gene expression linked to functional traits and environmental gradients in the South African shrub Protea repens. New Phytologist, 210(1), 295-309. https://doi.org/10.1111/nph.13761

Alexander, D. H., Novembre, J., \& Lange, K. (2009). Fast model-based estimation of ancestry in unrelated individuals. Genome Research, 19(9), 1655-1664. https://doi.org/10.1101/gr.094052.109

Almahasheer, H., Duarte, C. M., \& Irigoien, X. (2016). Phenology and growth dynamics of Avicennia marina in the Central Red Sea. Scientific Reports, 6, 37785. https://doi.org/10.1038/srep37785

Alvares, C. A., Stape, J. L., Sentelhas, P. C., de Gonçalves, J. L., \& Sparovek, G. (2013). Köppen's climate classification map for Brazil. Meteorologische Zeitschrift, 22(6), 711-728. https://doi. org/10.1127/0941-2948/2013/0507

Al-Whaibi, M. H. (2011). Plant heat-shock proteins: A mini review. Journal of King Saud University - Science, 23(2), 139-150. https://doi. org/10.1016/j.jksus.2010.06.022

Amorim, M. E., Schoener, T. W., Ramalho, G. C. C. S., Lins, A. C. R., PioviaScottd, J., \& Brandão, R. A. (2017). Lizards on newly created islands independently and rapidly adapt in morphology and diet. Proceedings of the National Academy of Sciences, 114(33), 8812-8816. https://doi. org/10.1073/pnas.1709080114

Antao, T., Lopes, A., Lopes, R. J., Beja-Pereira, A., \& Luikart, G. (2008). LOSITAN: A workbench to detect molecular adaptation based on a FST-outlier method. BMC Bioinformatics, 9(1), 1-5. https://doi. org/10.1186/1471-2105-9-323

Aranda, I., Cano, F. J., Gasco, A., Cochard, H., Nardini, A., Mancha, J. A., ... Sanchez-Gomez, D. (2014). Variation in photosynthetic performance and hydraulic architecture across European beech (Fagus sylvatica L.) populations supports the case for local adaptation to water stress.
Tree Physiology, 35(1), 34-46. https://doi.org/10.1093/treephys/ tpu101

Asner, G. P., Brodrick, P. G., Anderson, C. B., Vaughn, N., Knapp, D. E., \& Martin, R. E. (2016). Progressive forest canopy water loss during the 2012-2015 California drought. Proceedings of the National Academy of Sciences, 113(2), 249-255. https://doi.org/10.1073/pnas.15233 97113

Bang, W. Y., Hata, A., Jeong, I. S., Umeda, T., Masuda, T., Chen, J. I., ... Bahk, J. D. (2009). AtObgC, a plant ortholog of bacterial Obg, is a chloroplast-targeting GTPase essential for early embryogenesis. Plant Molecular Biology, 71(4-5), 379-390. https://doi.org/10.1007/ s11103-009-9529-3

Bartlett, M. K., Scoffoni, C., \& Sack, L. (2012). The determinants of leaf turgor loss point and prediction of drought tolerance of species and biomes: A global meta-analysis. Ecology Letters, 15, 393-405. https:// doi.org/10.1111/j.1461-0248.2012.01751.x

Beaumont, M. A., \& Nichols, R. A. (1996). Evaluating loci for use in the genetic analysis of population structure. Proceedings of the Royal Society B: Biological Sciences, 263(1377), 1619-1626. https://doi. org/10.1098/rspb.1996.0237

Bennett, A. C., McDowell, N. G., Allen, C. D., \& Anderson-Teixeira, K. J. (2015). Larger trees suffer most during drought in forests worldwide. Nature Plants, 1, 1-5. https://doi.org/10.1038/NPLAN TS.2015.139

Berardini, T. Z., Reiser, L., Li, D., Mezheritsky, Y., Muller, R., Strait, E., \& Huala, E. (2015). The Arabidopsis information resource: Making and mining the "Gold Standard" annotated reference plant genome. Genesis, 53, 474-485. https://doi.org/10.1002/dvg.22877

Blake, J. A., Christie, K. R., Dolan, M. E., Drabkin, H. J., Hill, D. P., Ni, L., ... Westerfeld, M. (2015). Gene ontology consortium: Going forward. Nucleic Acids Research, 43, D1049-D1056. https://doi.org/10.1093/ nar/gku1179

Bohne, A. V., Schwenkert, S., Grimm, B., \& Nickelsen, J. (2016). Roles of tetratricopeptide repeat proteins in biogenesis of the photosynthetic apparatus. International Review of Cell and Molecular Biology, 324, 187-227. https://doi.org/10.1016/bs.ircmb.2016.01.005

Camacho, C., Coulouris, G., Avagyan, V., Ma, N., Papadopoulos, J., Bealer, K., \&Madden, T.L. (2009). BLAST+:Architectureand applications.BMC Bioinformatics, 10, 421. https://doi.org/10.1186/1471-2105-10-421

Charng, Y. Y., Liu, H. C., Liu, N. Y., Chi, W. T., Wang, C. N., Chang, S. H., \& Wang, T. T. (2006). A heat-inducible transcription factor, HsfA2, is required for extension of acquired thermotolerance in Arabidopsis. Plant Physiology, 143(1), 251-262. https://doi.org/10.1104/pp.106.091322

Chaves, M. M., Flexas, J., \& Pinheiro, C. (2009). Photosynthesis under drought and salt stress: Regulation mechanisms from whole plant to cell. Annals of Botany, 103(4), 551-560. https://doi.org/10.1093/aob/ mcn125

Chaves, M. M., Maroco, J. P., \& Pereira, J. S. (2003). Understanding plant responses to drought - from genes to the whole plant. Functional Plant Biology, 30(3), 239-264. https://doi.org/10.1071/ FP02076

Cho, L. H., Yoon, J., \& An, G. (2017). The control of flowering time by environmental factors. Plant Journal, 90(4), 708-719. https://doi. org/10.1111/tpj.13461

Choat, B., Brodribb, T. J., Brodersen, C. R., Duursma, R. A., López, R., \& Medlyn, B. E. (2018). Triggers of tree mortality under drought. Nature, 558(7711), 531-539. https://doi.org/10.1038/s41586-018-0240-x

Ciemer, C., Boers, N., Hirota, M., Kurths, J., Müller-Hansen, F., Oliveira, R. S., \& Winkelmann, R. (2019). Higher resilience to climatic disturbances in tropical vegetation exposed to more variable rainfall. Nature Geoscience, 12, 174-179. https://doi.org/10.1038/ s41561-019-0312-z

Clough, B. F., Sim, R. G., Inlet, T., Bay, M., \& Rivers, I. (1989). Oecologia of mangroves in response to salinity and vapour pressure deficit. Oecologia, 459, 38-44. 
Cohen, M. C. L., \& Lara, R. J. (2003). Temporal changes of mangrove vegetation boundaries in Amazonia: Application of GIS and remote sensing techniques. Wetlands Ecology and Management, 11(4), 223-231. https://doi.org/10.1023/A:1025007331075

Corlett, R. T. (2016). The impacts of droughts in tropical forests. Trends in Plant Science, 21(7), 584-593. https://doi.org/10.1016/j.tplan ts.2016.02.003

Correll, M. J., Coveney, K. M., Raines, S. V., Mullen, J. L., Hangarter, R. P., \& Kiss, J. Z. (2003). Phytochromes play a role in phototropism and gravitropism in Arabidopsis roots. Advances in Space Research, 31(10), 2203-2210. https://doi.org/10.1016/S0273-1177(03)00245-X

Cruz, M. V., Mori, G. M., Signori-Müller, C., Silva, C. C., Oh, D.-H., Dassanayake, M., ... Souza, A. P. (2019). Local adaptation of a dominant coastal tree to freshwater availability and solar radiation suggested by genomic and ecophysiological approaches. Scientific Reports. https://doi.org/10.1038/s41598-019-56469-w [Epub ahead of print].

Cruz, M. V., Mori, G. M., Oh, D., Dassanayake, M., Zucchi, M. I., Oliveira, R. S., \& Souza, A. P. (2019). Data from: Molecular responses to freshwater limitation in the mangrove tree Avicennia germinans (Acanthaceae). Dryad Digital Repository, https://doi.org/10.5061/ dryad.pk0p2nghr.

da Costa, C. L., Galbraith, D., Almeida, S., Tanaka Portela, B. T., da Costa, M., de Athaydes Silva Junior, J., ...Meir, P. (2010). Effect of seven years of experimental drought on the aboveground biomass storage of an eastern Amazonian rainforest. New Phytologist, 187, 579-591. https://doi.org/10.1111/j.1469-8137.2010.03309.x

Danecek, P., Auton, A., Abecasis, G., Albers, C. A., Banks, E., DePristo M. A., ... Durbin, R. (2011). The variant call format and VCFtools. Bioinformatics, 27(15), 2156-2158. https://doi.org/10.1093/bioin formatics/btr330

Daniel, B., Pavkov-Keller, T., Steiner, B., Dordic, A., Gutmann, A., Nidetzky, B., ... Macheroux, P. (2015). Oxidation of monolignols by members of the berberine bridge enzyme family suggests a role in plant cell wall metabolism. Journal of Biological Chemistry, 290(30), 18770-18781. https://doi.org/10.1074/jbc.M115.659631

de Lorenzo, L., Merchan, F., Laporte, P., Thompson, R., Clarke, J., Sousa, C., \& Crespi, M. (2009). A novel plant leucine-rich repeat receptor kinase regulates the response of Medicago truncatula roots to salt stress. The Plant Cell, 21(1), 668-680. https://doi.org/10.1105/ tpc.108.059576

de Menezes, M. P. M., Berger, U., \& Mehlig, U. (2008). Mangrove vegetation in Amazonia: A review of studies from the coast of Pará and Maranhão States, north Brazil. Acta Amazonica, 38(3), 403-420. https://doi.org/10.1590/S0044-59672008000300004

Ding, Y., Liu, N., Virlouvet, L., Riethoven, J. J., Fromm, M., \& Avramova, Z. (2013). Four distinct types of dehydration stress memory genes in Arabidopsis thaliana. BMC Plant Biology, 13(1), 229. https://doi. org/10.1186/1471-2229-13-229

Donihue, C. M., Herrel, A., Fabre, A.-C., Kamath, A., Geneva, A. J., Schoener, T. W., ... Losos, J. B. (2018). Hurricane-induced selection on the morphology of an island lizard. Nature, 560(7716), 88-91. https://doi.org/10.1038/s41586-018-0352-3

Donovan, L. A., Ludwig, F., Rosenthal, D. M., Rieseberg, L. H., \& Dudley, S. A. (2009). Phenotypic selection on leaf ecophysiological traits in Helianthus. New Phytologist, 183(3), 868-879. https://doi. org/10.1111/j.1469-8137.2009.02916.x

Duarte, C. M., Thampanya, U., Terrados, J., Geertz-Hansen, O., \& Fortes, M. D. (1999). The determination of the age and growth of SE Asian mangrove seedlings from internodal counts. Mangroves and Salt Marshes, 3(4), 251-257. https://doi.org/10.1023/A:1009967401337

Ellison, A. M., Farnsworth, E. J., \& Merkt, R. E. (1999). Origins of mangrove ecosystems and the mangrove biodiversity anomaly. Global Ecology and Biogeography, 8(2), 95-115. https://doi. org/10.1046/j.1466-822X.1999.00126.x
ElSayed, A. I., Rafudeen, M. S., \& Golldack, D. (2014). Physiological aspects of raffinose family oligosaccharides in plants: Protection against abiotic stress. Plant Biology, 16(1), 1-8. https://doi. org/10.1111/plb.12053

Etterson, J. R. (2004). Evolutionary potential of Chamaecrista fasciculata in relation to climate change. I. Clinal patterns of selection along and environmental gradient in the great plains. Evolution, 58(7), 1446-1458. https://doi.org/10.1111/j.0014-3820.2004.tb01726.x

Fan, L., Wang, G., Hu, W., Pantha, P., Tran, K.-N., Zhang, H., ... Qiu, Q.-S. (2018). Plant physiology and biochemistry transcriptomic view of survival during early seedling growth of the extremophyte Haloxylon ammodendron. Plant Physiology and Biochemistry, 132(9), 475-489. https://doi.org/10.1016/j.plaphy.2018.09.024

Finn, R. D., Bateman, A., Clements, J., Coggill, P., Eberhardt, R. Y., Eddy, S. R., ... Punta, M. (2014). Pfam: The protein families database. Nucleic Acids Research, 42(D1), 222-230. https://doi.org/10.1093/nar/gkt1223

Francisco, P. M., Mori, G. M., Alves, F. M., Tambarussi, E., \& De Souza, A. P. (2018). Population genetic structure, introgression, and hybridization in the genus Rhizophora along the Brazilian coast. Ecology and Evolution, 8(6), 3491-3504. https://doi.org/10.1002/ece3.3900

Frenne, P., Graae, B. J., Rodríguez-Sánchez, F., Kolb, A., Chabrerie, O., Decocq, G., ... Verheyen, K. (2013). Latitudinal gradients as natural laboratories to infer species' responses to temperature. Journal of Ecology, 101(3), 784-795. https://doi.org/10.1111/1365-2745.12074

Frichot, E., \& François, O. (2015). LEA: An R package for landscape and ecological association studies. Methods in Ecology and Evolution, 6(8), 925-929. https://doi.org/10.1111/2041-210X.12382

Frydman, J. (2001). Folding of newkly translated proteins in vivo: The role of molecular chaperones. Annual Review of Biochemistry, 701(1), 603-647.

Goudet, J. (2005). Hierfstat, a package for R to compute and test hierarchical F-statistics. Molecular Ecology Notes, 5(1), 184-186. https:// doi.org/10.1111/j.1471-8278

Gould, B. A., Chen, Y., \& Lowry, D. B. (2018). Gene regulatory divergence between locally adapted ecotypes in their native habitats. Molecular Ecology, 27(21), 4174-4188. https://doi.org/10.1111/mec.14852

Hacke, U. G., Sperry, J. S., Wheeler, J. K., \& Castro, L. (2006). Scaling of angiosperm xylem structure with safety and efficiency. Tree Physiology, 26(6), 689-701. https://doi.org/10.1093/treephys/26.6.689

Hatorangan, M. R., Laenen, B., Steige, K., Slotte, T., \& Köhler, C. (2016). Rapid evolution of genomic imprinting in two species of the Brassicaceae. The Plant Cell, 28(8), 1815-1827. https://doi. org/10.1105/tpc.16.00304

Heschel, M. S., \& Riginos, C. (2005). Mechanisms of selection for drought stress tolerance and avoidance in Impatiens capensis (Balsaminaceae). American Journal of Botany, 92(1), 37-44. https://doi.org/10.3732/ ajb.92.1.37

Hijmans, R. J., Cameron, S. E., Parra, J. L., Jones, P. G., \& Jarvis, A. (2005). Very high resolution interpolated climate surfaces for global land areas. International Journal of Climatology, 25(15), 1965-1978. https ://doi.org/10.1002/joc.1276

Holliday, J. A., Aitken, S. N., Cooke, J. E. K., Fady, B., González-Martínez, S. C., Heuertz, M., ... Plomion, C. (2017). Advances in ecological genomics in forest trees and applications to genetic resources conservation and breeding. Molecular Ecology, 26, 706-717. https://doi. org $/ 10.1111 / \mathrm{mec} .13963$

Huang, S., Chen, X., Li, M., Ao, K., Huang, S., Chen, X., ... Li, X. (2016). Plant TRAF proteins regulate NLR immune receptor turnover. Cell Host \& Microbe, 19(2), 204-215. https://doi.org/10.1016/j. chom.2016.01.005

Hussey, S. G., Mizrachi, E., Spokevicius, A. V., Bossinger, G., Berger, D. K., \& Myburg, A. A. (2011). SND2, a NAC transcription factor gene, regulates genes involved in secondary cell wall development in Arabidopsis fibres and increases fibre cell area in Eucalyptus. BMC Plant Biology, 11, 1-17. https://doi.org/10.1186/1471-2229-11-173 
Janiak, A., Kwaśniewski, M., \& Szarejko, I. (2016). Gene expression regulation in roots under drought. Journal of Experimental Botany, 67(4), 1003-1014. https://doi.org/10.1093/jxb/erv512

Jombart, T. (2008). Adegenet: A R package for the multivariate analysis of genetic markers. Bioinformatics, 24(11), 1403-1405. https://doi. org/10.1093/bioinformatics/btn129

Jombart, T., \& Ahmed, I. (2011). adegenet 1.3-1: New tools for the analysis of genome-wide SNP data. Bioinformatics, 27(21), 3070-3071. https://doi.org/10.1093/bioinformatics/btr521

Jombart, T., Devillard, S., \& Balloux, F. (2010). Discriminant analysis of principal components: A new method for the analysis of genetically structured populations. BMC Genetics, 11(1), 94. https://doi. org/10.1186/1471-2156-11-94

Kamvar, Z. N., Tabima, J. F., \& Grünwald, N. J. (2014). Poppr: An R package for genetic analysis of populations with clonal, partially clonal, and/or sexual reproduction. PeerJ, 2, e281. https://doi.org/10.7717/ peerj.281

Kawecki, T. J., \& Ebert, D. (2004). Conceptual issues in local adaptation. Ecology Letters, 7(12), 1225-1241. https://doi. org/10.1111/j.1461-0248.2004.00684.x

Keller, S. R., Soolanayakanahally, R. Y., Guy, R. D., Silim, S. N., Olson, M. S., \& Tiffin, P. (2011). Climate-driven local adaptation of ecophysiology and phenology in balsam poplar, Populus balsamifera L. (Salicaceae). American Journal of Botany, 98(1), 99-108. https://doi.org/10.3732/ ajb.1000317

Kenkel, C. D., \& Matz, M. V. (2016). Gene expression plasticity as a mechanism of coral adaptation to a variable environment. Nature Ecology \& Evolution, 1, 059667. https://doi.org/10.1038/ s41559-016-0014

Kitaya, Y., Yabuki, K., Kiyota, M., Tani, A., Hirano, T., \& Aiga, I. (2002). Gas exchange and oxygen concentration in pneumatophores and prop roots of four mangrove species. Trees, 16, 155-158. https://doi. org/10.1007/s00468-002-0167-5

Langmead, B., Trapnell, C., Pop, M., \& Salzberg, S. (2009). Ultrafast and memory-efficient alignment of short DNA sequences to the human genome. Genome Biology, 10(3), R25. https://doi.org/10.1186/ gb-2009-10-3-r25

Lara, R. J., \& Cohen, M. C. L. (2006). Sediment porewater salinity, inundation frequency and mangrove vegetation height in Bragança, North Brazil: An ecohydrology-based empirical model. Wetlands Ecology and Management, 14(4), 349-358. https://doi.org/10.1007/ s11273-005-4991-4

Lawlor, D. W. (2002). Limitation to photosynthesis in water-stressed leaves: Stomata vs. metabolism and the role of ATP. Annals of Botany, 89, 871-885. https://doi.org/10.1093/aob/mcf110

Li, W., \& Godzik, A. (2006). Cd-hit: A fast program for clustering and comparing large sets of protein or nucleotide sequences. Bioinformatics, 22(13), 1658-1659. https://doi.org/10.1093/bioinformatics/btl158

Lin, G., \& Sternberg, L. S. L. (1992). Comparative study of water uptake and photosynthetic gas exchange between scrub and fringe red mangroves, Rhizophora mangle L. Oecologia, 90(3), 399-403. https://doi. org/10.1007/BF00317697

Lotterhos, K. E., \& Whitlock, M. C. (2015). The relative power of genome scans to detect local adaptation depends on sampling design and statistical method. Molecular Ecology, 24(5), 1031-1046. https://doi. org/10.1111/mec.13100

Luu, K., Bazin, E., \& Blum, M. G. B. (2016). pcadapt: An R package to perform genome scans for selection based on principal component analysis. Molecular Ecology Resources, 33, 67-77. https://doi. org/10.1111/1755-0998.12592

Manfield, I. W., Devlin, P. F., Jen, C.-H., Westhead, D. R., \& Gilmartin, P. M. (2006). Conservation, convergence, and divergence of light-responsive, circadian-regulated, and tissue-specific expression patterns during evolution of the Arabidopsis GATA gene family. Plant Physiology, 143(2), 941-958. https://doi.org/10.1104/pp.106.090761
Mayr, E. (1963). Animal species and evolution (Belknap). Cambridge: Harvard University Press.

McAdam, S. A. M., \& Brodribb, T. J. (2015). The evolution of mechanisms driving the stomatal response to vapor pressure deficit. Plant Physiology, 167(3), 833-843. https://doi.org/10.1104/pp.114.252940

McDonough, M. A., Kadirvelraj, R., Harris, P., Poulsen, J. C. N., \& Larsen, S. (2004). Rhamnogalacturonan lyase reveals a unique three-domain modular structure for polysaccharide lyase family 4. FEBS Letters, 565(1-3), 188-194. https://doi.org/10.1016/j.febslet.2004.03.094

McDowell, N. G., \& Allen, C. D. (2015). Darcy's law predicts widespread forest mortality under climate warming. Nature Climate Change, 5(7), 669-672. https://doi.org/10.1038/nclimate2641

McRae, G. J. (1980). A simple procedure for calculating atmospheric water vapor concentration. Journal of the Air Pollution Control Association, 30(4), 394-394. https://doi.org/10.1080/00022470.1980.10464362

Moran, E. V., Hartig, F., \& Bell, D. M. (2016). Intraspecific trait variation across scales: Implications for understanding global change responses. Global Change Biology, 22(1), 137-150. https://doi. org/10.1111/gcb.13000

Mori, G. M., Zucchi, M. I., Sampaio, I., \& Souza, A. P. (2015). Species distribution and introgressive hybridization of two Avicennia species from the Western Hemisphere unveiled by phylogeographic patterns. BMC Evolutionary Biology, 15(1), 1-15. https://doi.org/10.1186/ s12862-015-0343-z

Mori, G. M., Zucchi, M. I., \& Souza, A. P. (2015). Multiple-geographicscale genetic structure of two mangrove tree species: The roles of mating system, hybridization, limited dispersal and extrinsic factors. PLoS ONE, 10, e0118710. https://doi.org/10.1371/journ al.pone.0118710

Moritz, C. (1999). Conservation units and translocations: Strategies for conserving evolutionary processes. Hereditas, 130(3), 217-228. https ://doi.org/10.1111/j.1601-5223.1999.00217.x

Moriya, Y., Itoh, M., Okuda, S., Yoshizawa, A. C., \& Kanehisa, M. (2007). KAAS: An automatic genome annotation and pathway reconstruction server. Nucleic Acids Research, 35, 182-185. https://doi.org/10.1093/ nar/gkm321

Müller, M., Kunz, H. H., Schroeder, J. I., Kemp, G., Young, H. S., \& Ekkehard Neuhaus, H. (2014). Decreased capacity for sodium export out of Arabidopsis chloroplasts impairs salt tolerance, photosynthesis and plant performance. Plant Journal, 78(4), 646-658. https://doi. org/10.1111/tpj.12501

Murata, Y., Mori, I. C., \& Munemasa, S. (2015). Diverse stomatal signaling and the signal integration mechanism. Annual Review of Plant Biology, 66(1), 369-392. https://doi.org/10.1146/annurev-arpla nt-043014-114707

Nadia, T. D. E. L., Menezes, N. L. D. E., \& Machado, I. C. (2013). Floral traits and reproduction of Avicennia schaueriana Moldenke (Acanthaceae): A generalist pollination system in the Lamiales. Plant Species Biology, 28(1), 70-80. https://doi.org/10.1111/j.1442-1984.2011.00361.x

Narum, S. R., \& Hess, J. E. (2011). Comparison of FST outlier tests for SNP loci under selection. Molecular Ecology Resources, 11, 184-194. https://doi.org/10.1111/j.1755-0998.2011.02987.x

Nascimento, W. R. Jr, Souza-Filho, P. W. M., Proisy, C., Lucas, R. M., \& Rosenqvist, A. (2013). Mapping changes in the largest continuous Amazonian mangrove belt using object-based classification of multisensor satellite imagery. Estuarine, Coastal and Shelf Science, 117, 83-93. https://doi.org/10.1016/j.ecss.2012.10.005

Nettel-Hernanz, A., Dodd, S. R., Ochoa-Zavala, M., Tovilla-Hernández, C., \& Días-Gallegos, J. R. (2013). Mating system analyses of tropical populations of the Black Mangrove, Avicennia germinans (L.) L. (Avicenniaceae). Botanical Sciences, 91(1), 115-117.

Nishizawa, A., Yabuta, Y., \& Shigeoka, S. (2008). Galactinol and raffinose constitute a novel function to protect plants from oxidative damage. Plant Physiology, 147(3), 1251-1263. https://doi.org/10.1104/ pp.108.122465 
Novick, K. A., Ficklin, D. L., Stoy, P. C., Williams, C. A., Bohrer, G., Oishi, A. C., ... Phillips, R. P. (2016). The increasing importance of atmospheric demand for ecosystem water and carbon fluxes. Nature Climate Change, 6(11), 1023-1027. https://doi.org/10.1038/nclimate3114

Ohgishi, M., Saji, K., Okada, K., \& Sakai, T. (2004). Functional analysis of each blue light receptor, cry1, cry2, phot1, and phot2, by using combinatorial multiple mutants in Arabidopsis. Proceedings of the National Academy of Sciences, 101(8), 2223-2228. https://doi.org/10.1073/ pnas.0305984101

O'Leary, N. A., Wright, M. W., Brister, J. R., Ciufo, S., Haddad, D., McVeigh, R., ... Pruitt, K. D. (2016). Reference sequence (RefSeq) database at NCBI: Current status, taxonomic expansion, and functional annotation. Nucleic Acids Research, 44, D733-D745. https:// doi.org/10.1093/nar/gkv1189

Oliveira, R. R., Viana, A. J. C., Reátegui, A. C. E., \& Vincentz, M. G. A. (2015). An efficient method for simultaneous extraction of high-quality RNA and DNA from various plant tissues. Genetics and Molecular Research, 14(4), 18828-18838. https://doi.org/10.4238/2015. December.28.32

Osland, M. J., Gabler, C. A., Grace, J. B., Day, R. H., McCoy, M. L., McLeod, J. L., ... Hartley, S. B. (2018). Climate and plant controls on soil organic matter in coastal wetlands. Global Change Biology, 24, 5361-5379. https://doi.org/10.1111/gcb.14376

Pagnussat, G. C., Yu, H.-J., Ngo, Q. A., Rajani, S., Mayalagu, S., Johnson, C. S., ... Sundaresan, V. (2005). Genetic and molecular identification of genes required for female gametophyte development and function in Arabidopsis. Development, 132(3), 603-614. https://doi.org/10.1242/ dev.01595

Patel, R. K., \& Jain, M. (2012). NGS QC toolkit: A toolkit for quality control of next generation sequencing data. PLoS ONE, 7(2), e30619. https://doi.org/10.1371/journal.pone.0030619

Pavey, S. A., Collin, H., Nosil, P., \& Rogers, S. M. (2010). The role of gene expression in ecological speciation. Annals of the New York Academy of Sciences, 1206, 110-129. https://doi. org/10.1111/j.1749-6632.2010.05765.x

Pedmale, U. V., Huang, S.-S., Zander, M., Cole, B. J., Hetzel, J., Ljung, K., ... Chory, J. (2016). Cryptochromes interact directly with PIFs to control plant growth in limiting blue light. Cell, 164(1-2), 233-245. https:// doi.org/10.1016/j.cell.2015.12.018

Pesquet, E., Korolev, A. V., Calder, G., \& Lloyd, C. W. (2010). The microtubule-associated protein AtMAP70-5 regulates secondary wall patterning in Arabidopsis wood cells. Current Biology, 20(8), 744-749. https://doi.org/10.1016/j.cub.2010.02.057

Phillips, O. L., Aragao, L. E. O. C., Lewis, S. L., Fisher, J. B., Lloyd, J., LopezGonzalez, G., ... Torres-Lezama, A. (2009). Drought sensitivity of the amazon rainforest. Science, 323(5919), 1344-1347. https://doi. org/10.1126/science.1164033

Phillips, O. L., van der Heijden, G., Lewis, S. L., López-González, G., Aragão, L. E. O. C., Lloyd, J., ... Vilanova, E. (2010). Drought-mortality relationships for tropical forests. New Phytologist, 187, 631-646. https://doi.org/10.1111/j.1469-8137.2010.03359.x

Pieslinger, A. M., Hoepflinger, M. C., \& Tenhaken, R. (2010). Cloning of glucuronokinase from Arabidopsis thaliana, the last missing enzyme of the myo-inositol oxygenase pathway to nucleotide sugars. Journal of Biological Chemistry, 285(5), 2902-2910. https://doi.org/10.1074/ jbc.M109.069369

Polidoro, B. A., Carpenter, K. E., Collins, L., Duke, N. C., Ellison, A. M., Ellison, J. C., ... Yong, J. W. H. (2010). The loss of species: Mangrove extinction risk and geographic areas of global concern. PLoS ONE, 5(4), e10095. https://doi.org/10.1371/journal.pone.0010095

Powell, T. L., Wheeler, J. K., de Oliveira, A. A. R., da Costa, A. C. L., Saleska, S. R., Meir, P., \& Moorcroft, P. R. (2017). Differences in xylem and leaf hydraulic traits explain differences in drought tolerance among mature Amazon rainforest trees. Global Change Biology, 23(10), 4280-4293. https://doi.org/10.1111/gcb.13731
Pranchai, A., Jenke, M., Vogt, J., Grueters, U., Yue, L., Mehlig, U., ... Berger, U. (2017). Density-dependent shift from facilitation to competition in a dwarf Avicennia germinans forest. Wetlands Ecology and Management, 26(2), 139-150. https://doi.org/10.1007/ s11273-017-9561-z

Privat, I., Hakimi, M. A., Buhot, L., Favory, J. J., \& Lerbs-Mache, S. (2003). Characterization of Arabidopsis plastid sigma-like transcription factors SIG1, SIG2 and SIG3. Plant Molecular Biology, 51(3), 385-399. https://doi.org/10.1023/A:1022095017355

Ramírez-Valiente, J. A., Deacon, N. J., Etterson, J., Center, A., Sparks, J. P., Sparks, K. L., ... Cavender-Bares, J. (2018). Natural selection and neutral evolutionary processes contribute to genetic divergence in leaf traits across a precipitation gradient in the tropical oak Quercus oleoides. Molecular Ecology, 27, 2176-2192. https://doi.org/10.1111/ mec.14566

Reef, R., \& Lovelock, C. E. (2015). Regulation of water balance in Mangroves. Annals of Botany, 115(3), 385-395. https://doi. org/10.1093/aob/mcu174

Robinson, M. D., McCarthy, D. J., \& Smyth, G. K. (2010). edgeR: A Bioconductor package for differential expression analysis of digital gene expression data. Bioinformatics, 26(1), 139-140. https://doi. org/10.1093/bioinformatics/btp616

Rowland, L., da Costa, A. C. L., Galbraith, D. R., Oliveira, R. S., Binks, O. J., Oliveira, A. A. R., ... Meir, P. (2015). Death from drought in tropical forests is triggered by hydraulics not carbon starvation. Nature, 528(7580), 119-122. https://doi.org/10.1038/nature15539

Russello, M. A., Waterhouse, M. D., Etter, P. D., \& Johnson, E. A. (2015). From promise to practice: Pairing non-invasive sampling with genomics in conservation. PeerJ, 3, e1106. https://doi.org/10.7717/ peerj.1106

Savolainen, O., Lascoux, M., \& Merilä, J. (2013). Ecological genomics of local adaptation. Nature Reviews Genetics, 14(11), 807-820. https:// doi.org/10.1038/nrg3522

Sbrocco, E. J., \& Barber, P. H. (2013). MARSPEC: Ocean climate layers for marine spatial ecology. Ecology, 94(4), 979-979. https://doi. org/10.1890/12-1358.1

Schaeffer-Novelli, Y., Cintrón-Molero, G., Adaime, R. R., de Camargo, T. M., Cintron-Molero, G., \& de Camargo, T. M. (1990). Variability of mangrove ecosystems along the Brazilian coast. Estuaries, 13(2), 204-218. https://doi.org/10.2307/1351590

Schoener, T. W. (2011). The newest synthesis: Understanding the interplay of evolutionary and ecological dynamics. Science, 331(6016), 426-429. https://doi.org/10.1126/science.1193954

Simão, F. A., Waterhouse, R. M., loannidis, P., Kriventseva, E. V., \& Zdobnov, E. M. (2015). BUSCO: Assessing genome assembly and annotation completeness with single-copy orthologs. Bioinformatics, 31(19), 3210-3212. https://doi.org/10.1093/bioinformatics/btv351

Stone, S. L., Williams, L. A., Farmer, L. M., Vierstra, R. D., \& Callis, J. (2006). KEEP ON GOING, a RING E3 ligase essential for Arabidopsis growth and development, is involved in abscisic acid signaling. Plant Cell Online, 18(12), 3415-3428. https://doi.org/10.1105/tpc.106.046532

Stuart, S. A., Choat, B., Martin, K. C., Holbrook, N. M., \& Ball, M. C. (2007). The role of freezing in setting the latitudinal limits of mangrove forests. New Phytologist, 173(3), 576-583. https://doi. org/10.1111/j.1469-8137.2006.01938.x

Taji, T., Ohsumi, C., luchi, S., Seki, M., Kasuga, M., Kobayashi, M., ... Shinozaki, K. (2002). Important roles of drought- and cold-inducible genes for galactinol synthase in stress tolerance in Arabidopsis thaliana. Plant Journal, 29(4), 417-426. https://doi. org/10.1046/j.0960-7412.2001.01227.x

Takayama, K., Tateishi, Y., Murata, J., \& Kajita, T. (2008). Gene flow and population subdivision in a pantropical plant with sea-drifted seeds Hibiscus tiliaceus and its allied species: Evidence from microsatellite analyses. Molecular Ecology, 17(11), 2730-2742. https://doi. org/10.1111/j.1365-294X.2008.03799.x 
ten Hove, C. A., Bochdanovits, Z., Jansweijer, V. M. A., Koning, F. G., Berke, L., Sanchez-Perez, G. F., ... Heidstra, R. (2011). Probing the roles of LRR RLK genes in Arabidopsis thaliana roots using a custom T-DNA insertion set. Plant Molecular Biology, 76(1-2), 69-83. https:// doi.org/10.1007/s11103-011-9769-x

Tomlinson, P. B. (1986). The botany of mangroves. New York, NY: Cambridge University Press.

Tyree, M. T., \& Sperry, J. S. (1989). Vulnerability of xylem to cavitation and embolism. Annual Review of Plant Physiology and Molecular Biology, 40, 19-38. https://doi.org/10.1146/annurev.pp.40.060189.000315

Urban, L., Aarrouf, J., \& Bidel, L. P. R. (2017). Assessing the effects of water deficit on photosynthesis using parameters derived from measurements of leaf gas exchange and of chlorophyll a fluorescence. Frontiers in Plant Science, 8(2068). https://doi.org/10.3389/ fpls.2017.02068

Van der Does, D., Boutrot, F., Engelsdorf, T., Rhodes, J., McKenna, J. F., Vernhettes, S., ... Zipfel, C. (2017). The Arabidopsis leucine-rich repeat receptor kinase MIK2/LRR-KISS connects cell wall integrity sensing, root growth and response to abiotic and biotic stresses. PLOS Genetics, 13(6), 1-27. https://doi.org/10.1371/journal.pgen.1006832

Vogt, J., Lin, Y., Pranchai, A., Frohberg, P., Mehlig, U., \& Berger, U. (2014). The importance of conspecific facilitation during recruitment and regeneration: A case study in degraded mangroves. Basic and Applied Ecology, 15(8), 651-660. https://doi.org/10.1016/j.baae.2014.09.005

Walsh, B., \& Blows, M. W. (2009). Abundant genetic variation + strong selection = multivariate genetic constraints: a geometric view of adaptation. Annual Review of Ecology, Evolution, and Systematics, 40(1), 41-59. https://doi.org/10.1146/annurev.ecolsys.110308.120242

Walsh, P., Bursać, D., Law, Y. C., Cyr, D., \& Lithgow, T. (2004). The J-protein family: Modulating protein assembly, disassembly and translocation. EMBO Reports, 5(6), 567-571. https://doi.org/10.1038/ sj.embor.7400172

Wang, S., Chang, Y., \& Ellis, B. (2016). Overview of OVATE FAMILY PROTEINS, a novel class of plant-specific growth regulators. Frontiers in Plant Science, 7, 1-8. https://doi.org/10.3389/fpls.2016.00417

Wang, S., Chang, Y., Guo, J., \& Chen, J. G. (2007). Arabidopsis ovate family protein 1 is a transcriptional repressor that suppresses cell elongation. Plant Journal, 50(5), 858-872. https://doi. org/10.1111/j.1365-313X.2007.03096.x
Wee, A. K. S., Takayama, K., Asakawa, T., Thompson, B., Onrizal, S., ... Webb, E. L. (2014). Oceanic currents, not land masses, maintain the genetic structure of the mangrove Rhizophora mucronata Lam. (Rhizophoraceae) in Southeast Asia. Journal of Biogeography, 41(5), 954-964. https://doi.org/10.1111/jbi.12263

Wolf, J. B. W., Lindell, J., \& Backstrom, N. (2010). Speciation genetics: Current status and evolving approaches. Philosophical Transactions of the Royal Society B: Biological Sciences, 365(1547), 1717-1733. https ://doi.org/10.1098/rstb.2010.0023

Yan, Y.-B., Duke, N., \& Sun, M. (2016). Comparative analysis of the pattern of population genetic diversity in three Indo-West Pacific Rhizophora mangrove species. Frontiers in Plant Science, 7, 1434. https ://doi.org/10.3389/fpls.2016.01434

Young, M. D., Wakefield, M. J., Smyth, G. K., \& Oshlack, A. (2010). Gene ontology analysis for RNA-seq: Accounting for selection bias. Genome Biology, 11(2), R14. https://doi.org/10.1186/gb-2010-11-2-r14

Zhang, C., Zhang, L., Zhang, S., Zhu, S., Wu, P., Chen, Y., ... Wu, G. (2015). Global analysis of gene expression profiles in physic nut (Jatropha curcas L.) seedlings exposed to drought stress. BMC Plant Biology, 15(1), 1-14. https://doi.org/10.1186/s12870-014-0397-x

Zhong, R., Lee, C., Zhou, J., McCarthy, R. L., \& Ye, Z.-H. (2008). A battery of transcription factors involved in the regulation of secondary cell wall biosynthesis in Arabidopsis. The Plant Cell Online, 20(10), 27632782. https://doi.org/10.1105/tpc.108.061325

\section{SUPPORTING INFORMATION}

Additional supporting information may be found online in the Supporting Information section.

How to cite this article: Cruz MV, Mori GM, Oh D-H, et al. Molecular responses to freshwater limitation in the mangrove tree Avicennia germinans (Acanthaceae). Mol Ecol. 2020;29: 344-362. https://doi.org/10.1111/mec.15330 